\title{
Impact of soil map specifications for European climate simulations
}

\author{
Journal Article
}

Author(s):

Guillod, Benoît (D); Davin, Edouard Léopold (D); Kündig, Christine; Smiatek, Gerhard; Seneviratne, Sonia I. (D)

Publication date:

2013-01

Permanent link:

https://doi.org/10.3929/ethz-b-000056331

Rights / license:

In Copyright - Non-Commercial Use Permitted

Originally published in:

Climate Dynamics 40(1-2), https://doi.org/10.1007/s00382-012-1395-z 


\title{
Impact of soil map specifications for European climate simulations
}

\author{
Benoit P. Guillod · Edouard L. Davin • \\ Christine Kündig • Gerhard Smiatek • \\ Sonia I. Seneviratne
}

Received: 6 October 2011/Accepted: 8 May 2012/Published online: 14 June 2012

(C) Springer-Verlag 2012

\begin{abstract}
Soil physical characteristics can influence terrestrial hydrology and the energy balance and may thus affect land-atmosphere exchanges. However, only few studies have investigated the importance of soil textures for climate. In this study, we examine the impact of soil texture specification in a regional climate model. We perform climate simulations over Europe using soil maps derived from two different sources: the soil map of the world from the Food and Agricultural Organization and the European Soil Database from the European Commission Joint Research Center. These simulations highlight the importance of the specified soil texture in summer, with differences of up to $2{ }^{\circ} \mathrm{C}$ in mean 2-m temperature and $20 \%$ in precipitation resulting from changes in the partitioning of energy at the land surface into sensible and latent heat flux. Furthermore, we perform additional simulations where individual soil parameters are perturbed in order to understand their role for summer climate. These simulations highlight the importance of the vertical profile of soil moisture for evapotranspiration. Parameters affecting the latter are hydraulic diffusivity parameters, field capacity
\end{abstract}

B. P. Guillod $(\varangle) \cdot$ E. L. Davin · C. Kündig · S. I. Seneviratne Institute for Atmospheric and Climate Science, ETH Zurich, Zürich, Switzerland

e-mail: benoit.guillod@env.ethz.ch

S. I. Seneviratne

e-mail: sonia.seneviratne@env.ethz.ch

Present Address:

C. Kündig

EAWAG, Swiss Federal Institute of Aquatic Science

and Technology, Dübendorf, Switzerland

G. Smiatek

Institute for Meteorology and Climate Research, Karlsruhe Institute of Technology, Garmisch-Partenkirschen, Germany and plant wilting point. Our study highlights the importance of soil properties for climate simulations. Given the uncertainty associated with the geographical distribution of soil texture and the resulting differences between maps from different sources, efforts to improve existing databases are needed. In addition, climate models would benefit from tackling unresolved issues in land-surface modeling related to the high spatial variability in soil parameters, both horizontally and vertically, and to limitations of the concept of soil textural class.

Keywords Soil maps - Regional climate modelling · COSMO-CLM - Land surface modelling . Land-atmosphere interactions $\cdot$ Soil hydrology

\section{Introduction}

Global and regional climate simulations are subject to large uncertainties. These uncertainties relate to, on the one hand, model formulation and, on the other hand, to input parameters used in models, in particular those describing surface characteristics. These parameters are generally linked to vegetation or soil characteristics. Many studies have focused on the role of vegetation properties (e.g. LAI, stomatal conductance, root depth) due to increasing interest in the impact of land cover change on climate (e.g. Bonan 2008; Pitman et al. 2009), which led to more detailed and accurate maps of these properties (e.g. Lawrence and Chase 2007). On the contrary, few studies have investigated the role of soil parameters (such as porosity, heat capacity or hydraulic conductivity) on climate, although it remains unclear which of plant or soil parameters can impact climate more strongly. While some studies have suggested that vegetation parameters are indeed important (Mölders 2005), 
others have shown that soil parameters could matter as much (Osborne et al. 2004) or even more (Richter et al. 2004). Moreover, studies have shown that some soil physical properties, in particular infiltration rate, porosity or hydraulic conductivity, can change depending on e.g. crops, crop management and land clearing and use (Uhland 1950; Ghuman et al. 1991; Alegre and Cassel 1996; Zimmermann et al. 2006). A few studies have already highlighted their non-negligible role for exchanges of water and energy at the surface (Anders and Rockel 2009; Seneviratne et al. 2006b). In particular, soil properties influence soil moisture (SM) which plays a crucial role for summer climate in midlatitude regions, through its memory and feedbacks to the atmosphere (Seneviratne et al. 2010). Most notably, SM controls evapotranspiration $(E)$ in these regions and, therefore, the partitioning of energy at the surface between sensible $(H)$ and latent $(\lambda E)$ heat fluxes, directly influencing near-surface temperature and humidity. In spite of the recognized importance of soil moisture, several issues related to soil physical parameters remain unresolved.

First of all, soil parameters are usually assigned as attributes of soil classes that refer to the soil texture (Teuling et al. 2009). However, the range of a soil parameter can be rather large, even within a given soil class; in fact, its variability within a soil class is often larger than its variability between the classes (Mölders 2005; Teuling et al. 2009). Moreover, most parameters are model dependent (Kahan et al. 2006). For instance, even a basic parameter such as the water-holding capacity is highly variable between state-of-the-art AGCMs despite being long recognized as a key parameter for land-climate interactions (Seneviratne et al. 2006b).

In addition to these issues linked to the attribution of parameter values to the different soil classes, several data bases of the geographical distribution of soil classes exist, of which the FAO soil map of the world (FAO/UNESCO 1974) is the most commonly used global dataset (Smiatek et al. 2008). Nevertheless, alternative products exist at regional scale, some of which have a higher resolution and, in some cases, are based on more recent and detailed information; in Europe, such a product is the European Soil Database (ESDB), released by the European Commission Joint Research Center (JRC) (European Commission and the European Soil Bureau Network 2004).

In the present study, we provide a detailed investigation of the role of soil parameters in regional climate simulations for the European continent. First, we compare simulations with a Regional Climate Model (RCM) with soil maps derived from two different sources to assess the potential impact of the soil map itself. We then analyze the impact of individual soil parameters on the local climate with the help of additional simulations to identify key parameters.
This paper is structured as follows: Sect. 2 describes the model (2.1) as well as the conducted experiments (2.2). Section 3 presents the results from the comparison of the impact of different soil maps on summer climate (3.1) and the role of individual soil parameters (3.2). Finally, the main findings are summarized and discussed in Sect. 4.

\section{Experimental setup}

\subsection{COSMO-CLM}

COSMO-CLM (Rockel et al. 2008) is a non-hydrostatic RCM developed jointly by the COnsortium for Small-scale MOdeling (COSMO) and the Climate Limited-area Modeling Community (CLM-Community). It is based on the compressible non-hydrostatic governing equations of fluid dynamics, which are discretized on rotated geographical coordinates in the horizontal dimensions and terrain-following height coordinates in the vertical. A detailed technical documentation is available at http://www.cosmomodel.org/content/model/documentation/core/default.htm. In this study, we use version 4.8 of COSMO-CLM, which significantly improves model performance compared to a previous version 4.0 (Davin and Seneviratne 2012).

The LSM used in this version of the model is TERRA_ML, a multilayer soil model parameterizing evapotranspiration of plants and bare soil as well as heat transfer and water transport in the soil (see Appendix 1 and Schrodin and Heise 2001; Grasselt et al. 2008). TERRA_ML is a second-generation land surface model, in which transpiration is modeled without explicit coupling with photosynthesis. More specifically, the evapotranspiration parameterization is derived from the BATS model (Dickinson 1984), which is more empirical and less physically based than current third-generation LSMs.

Most relevant for this study is the dependence of the parameterization in TERRA_ML on a set of parameters defined for eight different soil classes representing a wide range of soil textures, including two special classes (ice, rock) and six standard classes (sand, sandy loam, loam, loamy clay, clay and peat). 15 parameters are associated to each soil class and their respective values are listed in Table 1.

\subsection{Experiments}

In this study, we analyze a set of simulations with COSMO-CLM. These simulations differ only in the applied soil maps and/or in the look-up table of the soil parameters corresponding to each soil class. The rest of the setup is the same throughout the experiments, including the 
Table 1 Look-up table of soil parameters for each soil class in TERRA_ML

\begin{tabular}{|c|c|c|c|c|c|c|c|c|c|}
\hline & & Ice & Rock & $\begin{array}{l}\text { S } \\
\text { Sand }\end{array}$ & $\begin{array}{l}\text { SL } \\
\text { Sandy loam }\end{array}$ & $\begin{array}{l}\text { L } \\
\text { Loam }\end{array}$ & $\begin{array}{l}\text { LC } \\
\text { Loamy clay }\end{array}$ & $\begin{array}{l}\mathrm{C} \\
\text { Clay }\end{array}$ & Peat \\
\hline 1 & Volume of voids $\theta_{\mathrm{PV}}(-)$ & - & - & 0.364 & 0.445 & 0.455 & 0.475 & 0.507 & 0.863 \\
\hline 2 & Field capacity $\theta_{\mathrm{FC}}(-)$ & - & - & 0.196 & 0.260 & 0.340 & 0.370 & 0.463 & 0.763 \\
\hline 3 & Permanent wilting point $\theta_{\mathrm{PWP}}(-)$ & - & - & 0.042 & 0.100 & 0.110 & 0.185 & 0.257 & 0.265 \\
\hline 4 & Air dryness point $\theta_{\mathrm{ADP}}(-)$ & - & - & 0.012 & 0.030 & 0.035 & 0.060 & 0.065 & 0.098 \\
\hline 5 & Minimum infiltration rate $I_{k 2}\left(\mathrm{~kg} /\left(\mathrm{m}^{2} \mathrm{~s}\right)\right]$ & - & - & 0.0035 & 0.0023 & 0.0010 & 0.0006 & 0.0001 & 0.0002 \\
\hline 6 & Hydraulic diffusivity $D_{0}\left(10^{-9} \mathrm{~m}^{2} \mathrm{~s}\right)$ & - & - & 18400 & 3460 & 3570 & 1180 & 442 & 106 \\
\hline 7 & Hydraulic diffusivity $D_{1}(-)$ & - & - & -8.45 & -9.47 & -7.44 & -7.76 & -6.74 & -5.97 \\
\hline 8 & Hydraulic conductivity $K_{0}\left(10^{-9} \mathrm{~m} / \mathrm{s}\right)$ & - & - & 47900 & 9430 & 5310 & 764 & 17 & 58 \\
\hline 9 & Hydraulic conductivity $K_{1}(-)$ & - & - & -19.27 & -20.86 & -19.66 & -18.52 & -16.32 & -16.48 \\
\hline 10 & Heat capacity $\rho_{0} c_{0}\left(10^{6} \mathrm{~J} /\left(\mathrm{m}^{3} \mathrm{~K}\right)\right)$ & 1.92 & 2.10 & 1.28 & 1.35 & 1.42 & 1.50 & 1.63 & 0.58 \\
\hline 11 & Heat conductivity $\lambda_{0}(\mathrm{~W} /(\mathrm{Km}))$ & 2.26 & 2.41 & 0.30 & 0.28 & 0.25 & 0.21 & 0.18 & 0.06 \\
\hline 12 & Heat conductivity $\Delta \lambda(\mathrm{W} /(\mathrm{Km}))(-)$ & 0 & 0 & 2.40 & 2.40 & 1.58 & 1.55 & 1.50 & 0.50 \\
\hline 13 & Exponent $B(-)$ & 1 & 1 & 3.5 & 4.8 & 6.1 & 8.6 & 10 & 9 \\
\hline 14 & Albedo (-) & 0.7 & 0.3 & 0.3 & 0.25 & 0.25 & 0.25 & 0.25 & 0.2 \\
\hline 15 & Wet albedo (-) & - & - & 0.44 & 0.27 & 0.24 & 0.23 & 0.22 & 0.1 \\
\hline \multicolumn{2}{|c|}{ Available water capacity $\theta_{\mathrm{A}}=\left(\theta_{\mathrm{FC}}-\theta_{\mathrm{PWP}}\right)(-)$} & - & - & 0.154 & 0.160 & 0.230 & 0.185 & 0.206 & 0.498 \\
\hline
\end{tabular}

Corresponding values for the avaliable water capacity $\theta_{\mathrm{A}}=\left(\theta_{\mathrm{FC}}-\theta_{\mathrm{PWP}}\right)$ are also indicated. From Doms et al. (2011)

atmospheric part of the model. This allows to strictly isolate the effect of soil maps and/or soil parameters.

The configuration applied to all simulations is the following: The model is run over the European continent, including parts of North Africa and Western Russia (e.g. Fig. 1), with a horizontal resolution of $0.44^{\circ}(\sim 50 \mathrm{~km}), 32$ vertical levels and a time step of $240 \mathrm{~s}$. Initial and lateral boundary conditions are based on ERA-40 reanalysis data, except for the years 2002-2005 where ECMWF operational forecast analyses are used. The model is run for the period 1980-2005, where the first six years serve as a spinup in order to reach equilibrium, in particular to allow soil moisture to adjust to the modified conditions. The remaining 20 years (1986-2005) are used in the analysis. Although no ensemble runs were performed, the internal variability of the model is relatively well sampled given the simulated length.

The experiments can be divided into two sets of simulations with distinct objectives: The first set compares the impact of the choice between the two soil maps, while the second set investigates the involved physical processes by testing the role of individual soil parameters. These two sets of simulations are described in two separate sections.

\subsubsection{Comparison of impact of FAO and JRC soil maps}

The standard soil map used in COSMO-CLM is derived from the Digital Soil Map of the World (FAO 2003), which is available at a 5 arc minutes resolution and in geographical projection. It is based on the FAO map published in 1974 (FAO/UNESCO 1974). A more recent and better resolved product, the Soil Geographical Database of Eurasia (see Lambert et al. 2002), which is part of the European Soil Database, was released by the European Commission Joint Research Center (JRC) in 2006 (European Commission and the European Soil Bureau Network, 2004); it contains soil texture data over Europe at a 1-km resolution. More details about the conversion of the FAO and JRC products into TERRA_ML-compatible maps for use in simulations are given in Appendix 2.

In a first set of simulations we aim at investigating the sensitivity of regional climate simulations to the choice of the applied soil map. In a first simulation (FAO) we used the standard FAO map and in a second simulation (JRC) we replaced this standard map with the soil map from the JRC product. Figure 1 displays both soil maps as used in the two simulations. These differ in some regions, with coarser/finer soil textures in JRC compared to FAO as shown in Fig. 2. Note that the values of the soil parameters that are attributed to each soil class are shown in Table 1 and correspond to the standard values in TERRA_ML.

\subsubsection{Role of the different soil parameters}

To help understand the physical processes underlying the climate response to the modified soil class associated with the respective soil maps, we perform additional experiments which isolate the effect of specific soil parameters. 
Fig. 1 Soil class distribution based on the FAO soil map (left) and the JRC soil map (right). Soil classes are indicated on the right
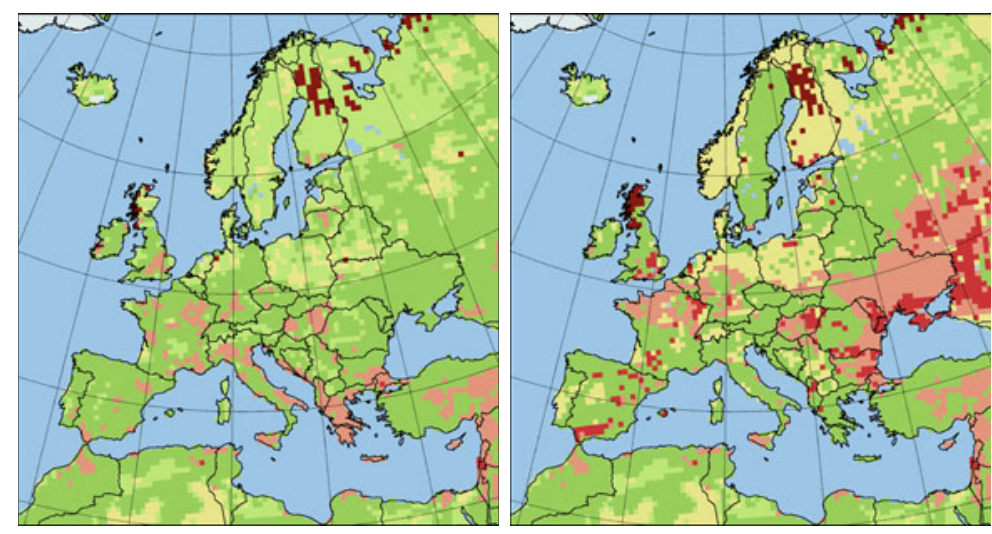
sea water peat clay $(C)$ loamy clay (LC) loam (L) sandy loam (SL) sand (S) rock ice

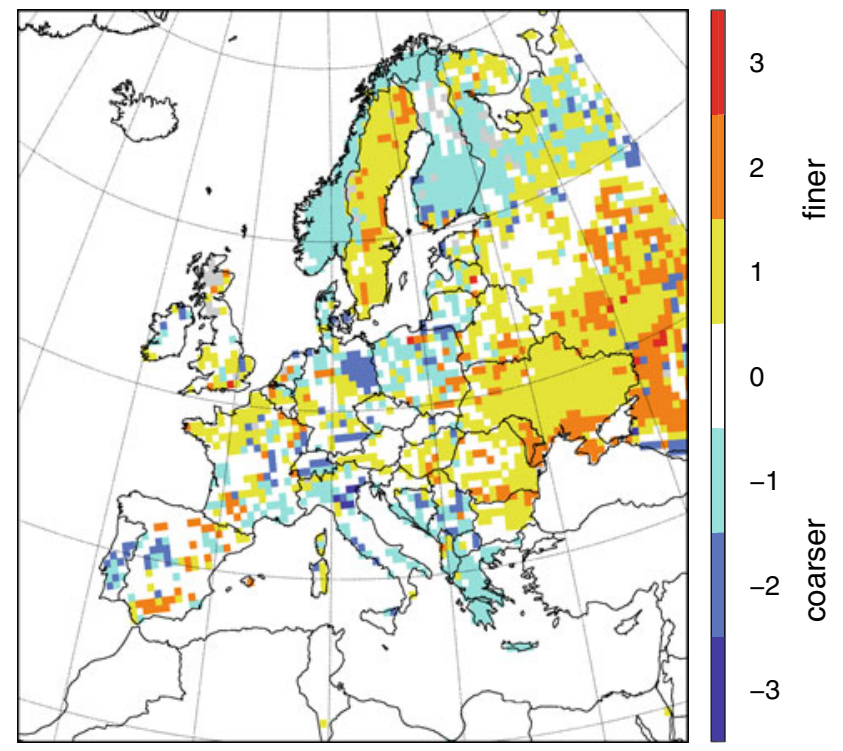

Fig. 2 Change in soil textural class expressed as JRC-FAO. Red (blue) colours indicate finer (coarser) soil grains in JRC compared to FAO. Grid points with special soil classes ("rock", "ice", "peat") on either map and which exhibit a change in soil class appear in grey

Although in each of these simulations the FAO soil map was used, soil class conversions (changes from one soil class to another) were introduced by modifying specific soil parameters for one soil class at a time.

We selected the following three representative soil class conversions (frequently occuring when changing the soil map from FAO to JRC):

- sandy loam to loam (experiments "SL2L")

- loam to loamy clay (experiments "L2LC")

- loam to clay (experiments "L2C")

For each of these conversions we examined the individual influence of the following sets of soil parameters:

- Field capacity $\theta_{\mathrm{FC}}$ and permanent wilting point $\theta_{\mathrm{PWP}}$ (experiments "WHC")

- Hydraulic conductivity parameters $K_{0}$ and $K_{1}$ (experiments "COND")
- Hydraulic diffusivity parameters $D_{0}$ and $D_{1}$ (experiments "DIFF")

Only hydrological parameters have been chosen since they cause most of the climate effect, as will be shown in Sect. 3.1. Note that, as described in the "Vertical soil water transport" in Appendix 1, hydraulic conductivity and hydraulic diffusivity are physically linked. Our experiments, however, allow us to disentangle the effect of gravity (COND) versus capillary forces (DIFF) on the vertical water transport.

In TERRA_ML, the hydraulic diffusivity $D_{w}$ is defined as a function of the soil liquid water content $\theta$, and $D_{0}$ and $D_{1}$ are constants in this function (see Eq. 18 in "Vertical soil water transport", Appendix 1). As a result, modifying $D_{0}$ and $D_{1}$ together changes the sensitivity of hydraulic diffusivity to soil moisture and, since these two parameters do not appear anywhere else in the model it seems reasonable to combine them together for our present purpose.

Since hydraulic conductivity $K_{w}$ is defined similarly to hydraulic diffusivity (see Eq. 19), $K_{0}$ and $K_{1}$ were also grouped together in a set of parameters. We note that, in addition to influencing $K_{w}, K_{0}$ also plays a role in the parameterization of bare soil evaporation (see Eqs. 5, 7).

Finally, the field capacity $\theta_{\text {FC }}$ and permanent wilting point $\theta_{\text {PWP }}$ are selected and modified together because of their role in controlling the amount of water available for plant transpiration (see Eq. 12 in Appendix 1). On the one hand, $\theta_{\mathrm{FC}}$ is the amount of water that remains in the soil after excess water has drained out. On the other hand, $\theta_{\text {PWP }}$ is the minimum amount of water necessary to prevent plants from wilting and below which almost no transpiration takes place anymore.

Note that, for several reasons, neither porosity (volume of void, $\left.\theta_{\mathrm{PV}}\right)$ nor air dryness point $\left(\theta_{\mathrm{ADP}}\right)$ were modified in our experiments. First, we want to isolate the effect of field capacity $\theta_{\mathrm{FC}}$ and permanent wilting point $\theta_{\mathrm{PWP}}$, which are expected to be most crucial for evapotranspiration (see Eq. 12). In addition, changes in $D_{w}$ and $K_{w}$ could arise from modifying $\theta_{\mathrm{PV}}$ and $\theta_{\mathrm{ADP}}$ (see Eqs. 18, 19), while 
modifying $\theta_{\mathrm{FC}}$ and $\theta_{\mathrm{PWP}}$ does not directly impact hydraulic diffusivity and conductivity, thus isolating more strictly the various influences.

The name of each experiment reflects the set of modified soil parameters and the involved soil class conversion. In total, combining three soil class conversions with three sets of parameters leads to nine additional simulations. All simulations are summarized in Table 2. For instance, for testing the impact of $\theta_{\text {PWP }}$ when modifying the soil class from "sandy loam" (in the FAO soil map) to "loam" (in the JRC soil map), the values of $\theta_{\mathrm{FC}}$ and $\theta_{\mathrm{PWP}}$ of the soil class "sandy loam" were replaced by those of "loam". This simulation is called WHC-SL2L. Note that the values of all other parameters are kept as in Table 1 for this simulation. Similarly, in two other simulations called COND-SL2L and DIFF-SL2L the hydraulic conductivity and diffusivity parameters, respectively, of "sandy loam" were set to the values of "loam". Thus, at the points where the soil class conversion SL2L occurs, the impact of the tested parameters on climate can be compared to the impact of changing the soil map, i.e. the impact of changing all parameters together.

A limitation of these simulations is that the changes affect all grid points with the corresponding soil class, while in JRC only some of these grid points are affected. In addition, grid points with other soil classes are not modified. Thus, these simulations are not entirely comparable to the full JRC experiment. However, the impact of these two differences is likely to be very restricted since the changes that we focus on in our analysis are mostly local (as shown in Sect. 3.1). Therefore, we assume that these small differences do not impact our results in a significant way.

Relative changes in selected soil parameter values for the three selected soil class conversions are displayed in Fig. 3. Note that although all the selected soil class conversions lead to a finer soil texture, not all parameters change in a similar way. As expected, both field capacity and permanent wilting point increase; by contrast, the resulting available water capacity $\theta_{A}=\left(\theta_{\mathrm{FC}}-\theta_{\mathrm{PWP}}\right)$, which represents the amount of water potentially available for plants, can either increase or decrease. Similarly, hydraulic diffusivity and conductivity parameters can change in either direction. However, since the final values of hydraulic conductivity and diffusivity depend on soil moisture as well, it is difficult to assess the overall change in these two parameters.

\section{Results}

Section 3.1 presents results from the comparison between simulations with both tested soil maps (FAO and JRC), while Sect. 3.2 presents results from additional simulations that investigate the role of individual soil parameters.

\subsection{Impact of the new JRC soil map (JRC vs. FAO)}

\subsubsection{Mean climate and surface fuxes}

Since the differences between simulations FAO and JRC are largest in summer (not shown), we concentrate on this period (June-August, JJA) for the whole analysis. Figure $4 \mathrm{a}, \mathrm{b}$ display changes in summer mean 2-m temperature and precipitation between the two simulations (JRC minus FAO). The region north of the Black Sea experiences warmer (up to $2 \mathrm{~K}$ ), drier (up to $0.5 \mathrm{~mm} /$ day) summer with the JRC soil map. On the other hand, the Baltic region (mainly Poland and Belarus) and the region over Italy and the Western Balkan states experience cooler (up to $1 \mathrm{~K}$ ), wetter (up to $0.4 \mathrm{~mm} /$ day) summer with this soil map. As shown in Table 3, changes in temperature clearly depend on the soil class conversion, while changes

Table 2 Summary of the simulations

\begin{tabular}{lll}
\hline Simulation name & soil map & loop-up table \\
\hline FAO & FAO & Standard \\
JRC & JRC & Standard \\
WHC-SL2L & FAO & $\theta_{\text {FC }}$ and $\theta_{\text {PWP }}$ of sandy loam replaced by respective values of loam \\
DIFF-SL2L & FAO & $D_{0}$ and $D_{1}$ of sandy loam replaced by respective values of loam \\
COND-SL2L & FAO & $K_{0}$ and $K_{1}$ of sandy loam replaced by respective values of loam \\
WHC-L2LC & FAO & $\theta_{\text {FC }}$ and $\theta_{\text {PWP }}$ of loam replaced by respective values of loamy clay \\
DIFF-L2LC & FAO & $D_{0}$ and $D_{1}$ of loam replaced by respective values of loamy clay \\
COND-L2LC & FAO & $K_{0}$ and $K_{1}$ of loam replaced by respective values of loamy clay \\
WHC-L2C & FAO & $\theta_{\text {FC }}$ and $\theta_{\text {PWP } \text { of loam replaced by respective values of clay }}$ \\
DIFF-L2C & FAO & $D_{0}$ and $D_{1}$ of loam replaced by respective values of clay \\
COND-L2C & FAO & $K_{0}$ and $K_{1}$ of loam replaced by respective values of clay
\end{tabular}

The standard look-up table is shown in Table 1, while other look-up tables are the same except for 2 parameters in one soil class 


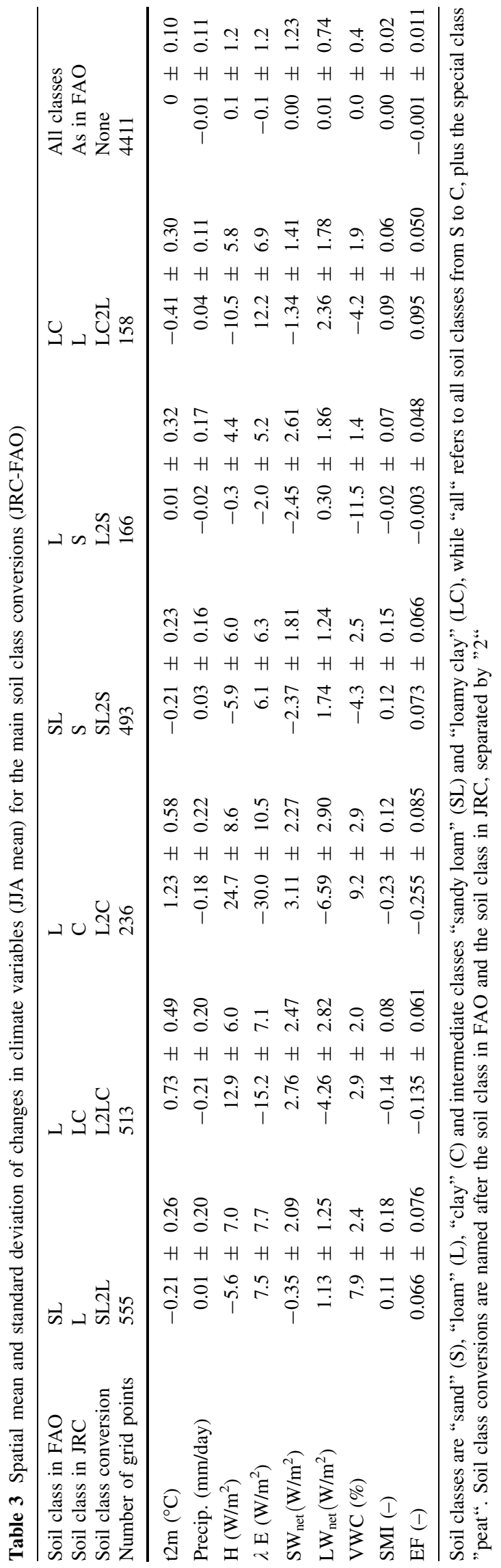

in precipitation are slightly less related to the soil class conversion pattern and thus more difficult to interpret.

To analyze the impact of soil types on the mean climate in the broader context of uncertainties in RCMs, Fig. 5a displays changes in mean 2-m temperature for selected regions as compared to the PRUDENCE multi-model ensemble (Jacob et al. 2007). We display the PRUDENCE inter-model interquartile range (referred to as PRUDENCE IQR, positive by definition and plotted from $-\mathrm{IQR} / 2$ to $+\mathrm{IQR} / 2$ ), which provides a measure of the spread among different RCMs for a given region. The overall effect of changing the soil map is small compared to the PRUDENCE IQR and, mostly, not significant, due to offsetting effects from different soil type conversions within a given region. On the other hand, when considering only a single soil type conversion, changes are often large and of similar magnitude as the PRUDENCE IQR, although always smaller. However, since none of the PRUDENCE regions covers the area exhibiting the strongest effect on climate (i.e. North of the Black Sea; only the Eastern European (EA) region covers part of it, but also includes a large area of cooling over Poland and Belarus), we added for comparison a region defined between 30 and $45^{\circ}$ East and 45 and $52^{\circ}$ North (BS). Although the PRUDENCE IQR over BS is not available, the impact is striking, with the change in mean temperature over the region due to the soil map being as large as the inter-model IQR from other regions. This shows that, in some regions, soil type specifications can lead to differences in mean summer climate as large as typical differences between RCMs.

The mechanisms controlling these differences are associated to changes in the hydrological properties of the soil. Changes in sensible $(H)$ and latent $(\lambda E)$ heat fluxes are large (up to more than $30 \mathrm{~W} / \mathrm{m}^{2}$, see Fig. $4 \mathrm{~g}$, $\mathrm{h}$ and Table 3) and, although they also mostly compensate each other (their sum is about 3-5 W/m $\mathrm{m}^{2}$, i.e. of the same order as net radiation), their properties explain temperature changes quite well. More specifically, the changes in these fluxes $(H$ and $\lambda E$ ) correspond to a modification of surface energy partitioning, expressed by the evaporative fraction $\mathrm{EF}=\lambda E /(H+\lambda E)$ shown in Fig. 4i. In regions with increased $\mathrm{EF}$, the part of the available energy at the surface which is used for evapotranspiration $(E$, expressed as $\lambda E$ in energy units) increases (i.e. $\lambda E$ increases and $\mathrm{H}$ decreases, given that the available energy $(\simeq H+\lambda E)$ remains approximately constant). This change in partitioning is confirmed by Fig. $7 \mathrm{a}$, where changes in $H$ and $\lambda E$ are plotted for the main soil class conversions: Changes in $H$ and $\lambda E$ are of similar magnitude and opposite sign. Therefore, EF is a good indicator of the changes in both fluxes. Since $H$ directly influences air temperature, 2-m temperature increases in regions of decreased $\mathrm{EF}$ and decreases in regions of increased EF, respectively. 


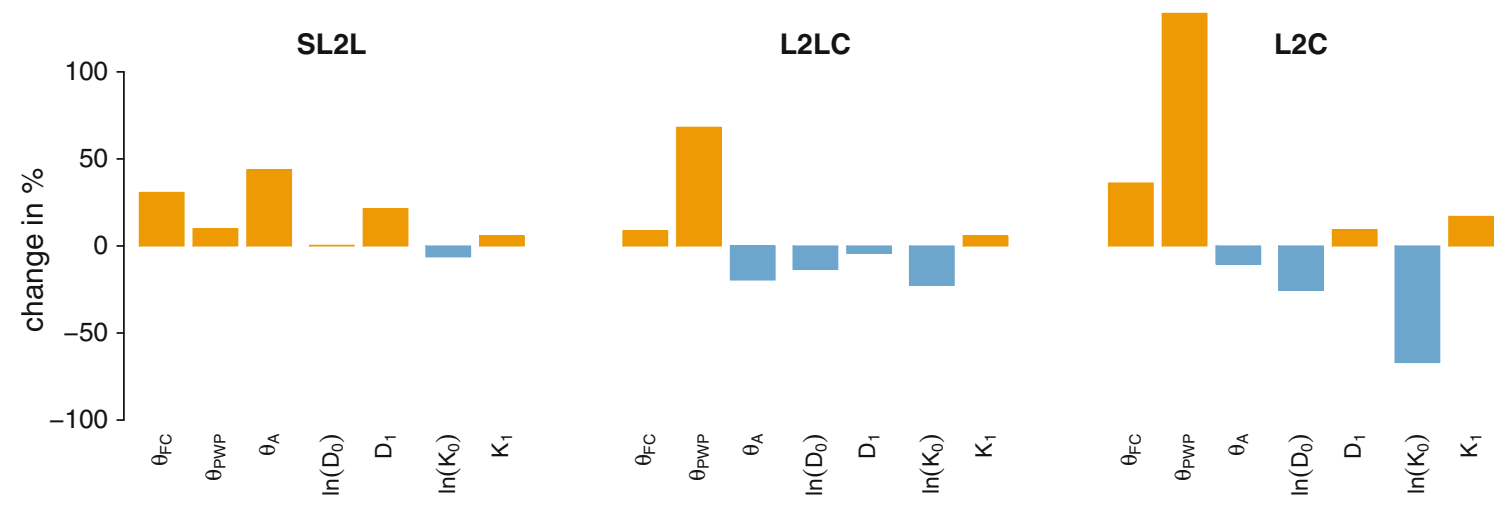

Fig. 3 Relative changes (expressed for $X$ as $\frac{X_{I R C}-X_{F A O}}{\left|X_{F A O}\right|}$ ) in selected soil parameters for 3 selected soil class conversions. Absolute values of each parameter for each soil class are given in Table 1

By contrast, radiative properties do not strongly affect the local climate in our simulations. First, changes in net shortwave and longwave radiation are in most cases smaller than changes in turbulent fluxes (Table 3). In addition, Fig. 4d, e, which show net longwave and shortwave radiation, emphasize that although there is a nonnegligible change in both radiation fluxes (up to $10 \mathrm{~W} / \mathrm{m}^{2}$ ), they mostly compensate each other (note the inverse scale). Thus, total net radiation only differs by about $3-5 \mathrm{~W} / \mathrm{m}^{2}$ (not shown). Furthermore, changes in net shortwave radiation are driven by changes in incoming direct shortwave radiation (solar radiation) due to changes in cloud cover (Fig. 4f), while changes in net longwave radiation result from changes in outgoing longwave radiation due to temperature changes (since longwave radiation emission is a function of temperature). We also note that changes in albedo are small for most soil class changes (see Table 1), which consolidates our interpretation.

In addition, like other studies that have shown that surface fluxes driven by soil moisture may influence atmospheric circulation (e.g. Fischer et al. 2007), we note slight changes in mean sea level pressure in our simulations (Fig. 4c). However, these changes are very small and they cannot explain the identified major changes in temperature and precipitation. Indeed, as shown in Table 3, the effects are local and grid points where the soil class is the same in the two simulations (i.e. conversion "none") do not exhibit any change in climate compared to other points.

\subsubsection{Soil moisture}

Surface energy partitioning in transitional climate regions usually depends on soil moisture (SM) since this variable controls $\lambda E$ and thus EF there (Seneviratne et al. 2010). SM can be expressed by different metrics. Two of them are used here. First, the Volumetric Water Content
(VWC) expresses SM as a volumetric fraction, i.e. $\mathrm{VWC}=\left(\frac{\text { volume of waterin } V}{V}\right)$ where $V$ is a soil volume. Second, Soil Moisture Index (SMI) expresses SM relative to field capacity $\theta_{\mathrm{FC}}$ and plant wilting point $\theta_{\mathrm{PWP}}$ as $\mathrm{SMI}=\frac{\theta-\theta_{\mathrm{PWP}}}{\theta_{\mathrm{FC}}-\theta_{\mathrm{PWP}}}$ where $\theta$ is $\mathrm{SM}$ expressed as VWC. In other words, SMI describes the amount of water within the available water capacity $\theta_{A}$ and therefore the water stress, with no stress for SMI $=1$ and no water available for $\mathrm{SMI}=0$ (Betts 2004; Seneviratne et al. 2010). The layers considered in this Section for both VWC and SMI cover the root depth, thus capturing the water stress for the plants and therefore transpiration (see Eq. 11).

As shown in Fig. 6a, changes in VWC over the root depth cannot explain changes in EF. Indeed, VWC increases over most regions, including north of the Black Sea and over the Baltic region, and decreases over other regions where EF increases (e.g. over Italy and the Western Balkan states). By contrast, SMI does explain these changes very well (Fig. 6b), with regions where EF and SMI increase (e.g. Baltic region, Italy and the Western Balkan states) and other regions where both EF and SMI decrease (e.g. north of the Black Sea). This better correspondence of SMI to EF, compared to that of VWC to $\mathrm{EF}$, is due to the changes in soil parameters (mainly $\theta_{\mathrm{FC}}$ and $\theta_{\mathrm{PWP}}$ ) which modify the sensitivity of $\mathrm{E}$ to VWC, while SMI accounts for these changes (especially for transpiration, through Eqs. 11, 12). This is in line with previous studies (see Seneviratne et al. 2010) showing that EF is better related to relative rather than absolute soil moisture content. Figure $7 \mathrm{~b}$ shows relative changes in these two variables for the main soil class conversions and confirms a relationship between them, although there is a large spread in the response of EF to changes in SMI.

This spread can be explained when comparing the respective maps of the two variables (SMI and EF; 
(a)

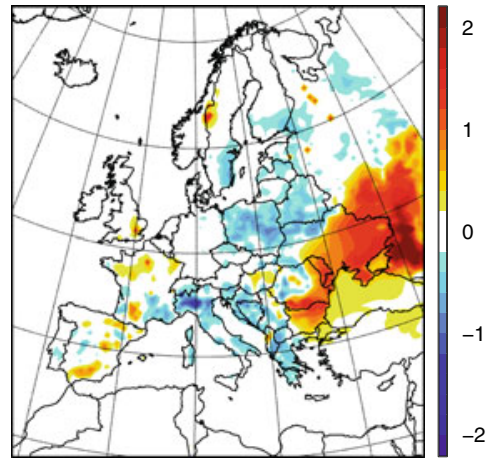

(d)

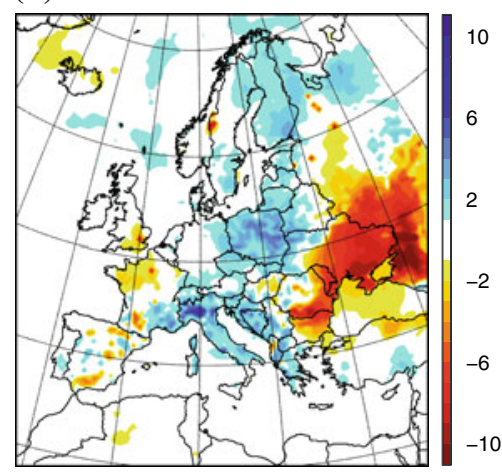

(g)

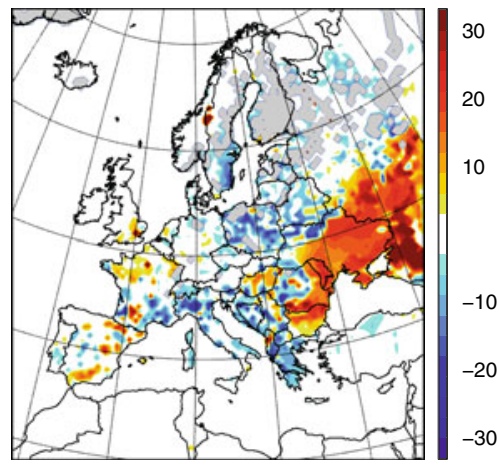

(b)

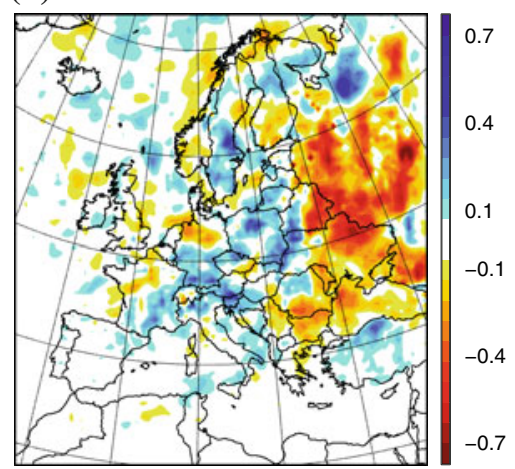

(e)

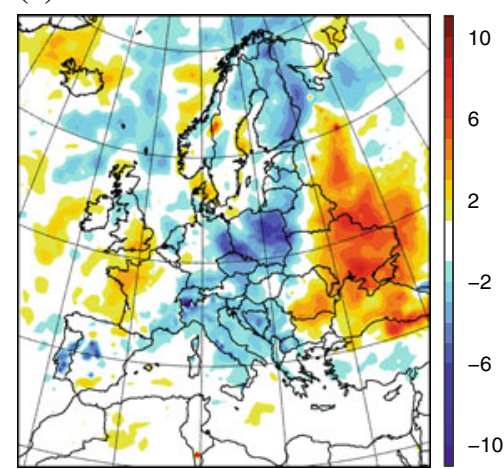

(h)

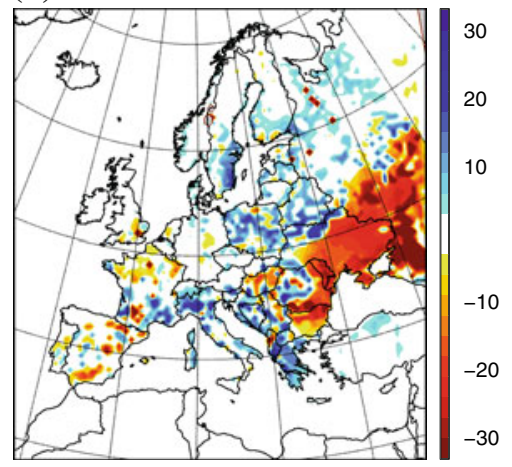

(c)

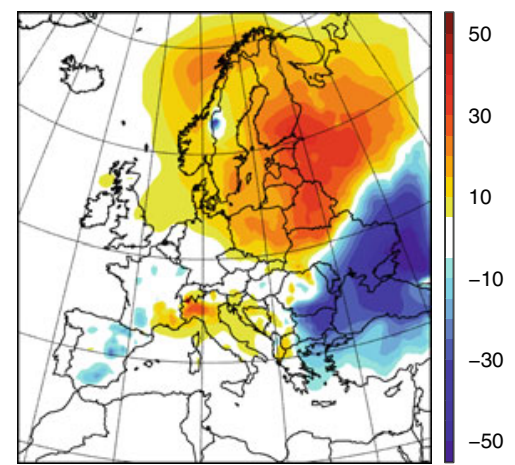

(f)

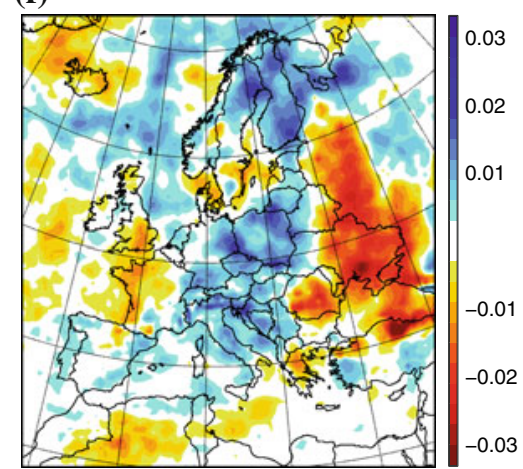

(i)

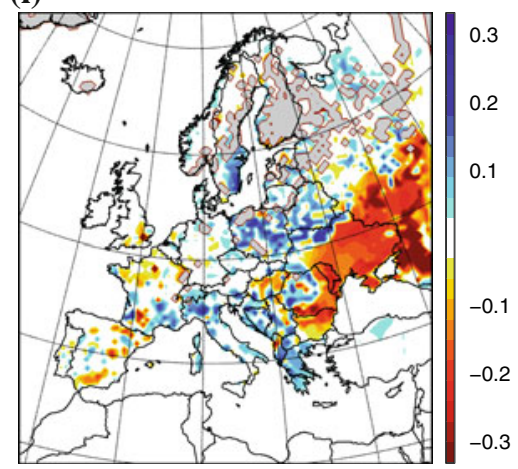

Fig. 4 Difference between JRC and FAO (JRC-FAO) for mean summer climate (JJA). Sensible and latent heat fluxes are computed only over land and at points where the respective mean value is positive in both simulations, while evaporative fraction is computed only at points where both turbulent fluxes are positive (gray shading indicates location where this is not the case). Note that a line

Figs. $6 \mathrm{~b}, 4 \mathrm{i}$, respectively). In spite of a good visual agreement in sign between the changes in SMI and EF (as well as $H$ and $\lambda E$ ), the intensities of these changes differ, with large changes in the two turbulent fluxes in southern Europe, where changes in SMI tend to be rather small. This explains most of the spread in Fig. $7 b$ and simply reflects the different evapotranspiration regimes. In the South, EF is limited by SMI and, therefore, even small SMI changes impact EF. In the North, EF tends to be rather radiation-limited; there, SMI does not play an smoothing has been applied for display purposes. a 2-m temperature $\left({ }^{\circ} \mathrm{C}\right)$, b Precipitation (mm/day), c Mean sea level pressure, d Net longwave radiation $\left(\mathrm{W} / \mathrm{m}^{2}\right)$, e Net shortwave radiation $\left(\mathrm{W} / \mathrm{m}^{2}\right)$, f Total cloud cover, $\mathbf{g}$ Sensible heat flux $\left(\mathrm{W} / \mathrm{m}^{2}\right)$, h Latent heat flux $\left(\mathrm{W} / \mathrm{m}^{2}\right)$, i Evaporative fraction

important role for the local climate. Thus, changes in EF are largest in the South. By contrast, although the latitudinal gradient in changes in SMI is less marked, it reflects the negative feedback loop between EF and SM: in the South, an increase in SM leads to an increase in EF, which then depletes SM, thus damping the initial SM increase. By contrast, in the North, an increase in SM does not strongly impact EF and this negative feedback loop does not exist. This explains why changes in SMI are largest in the North and relatively small in the South. 
(a)

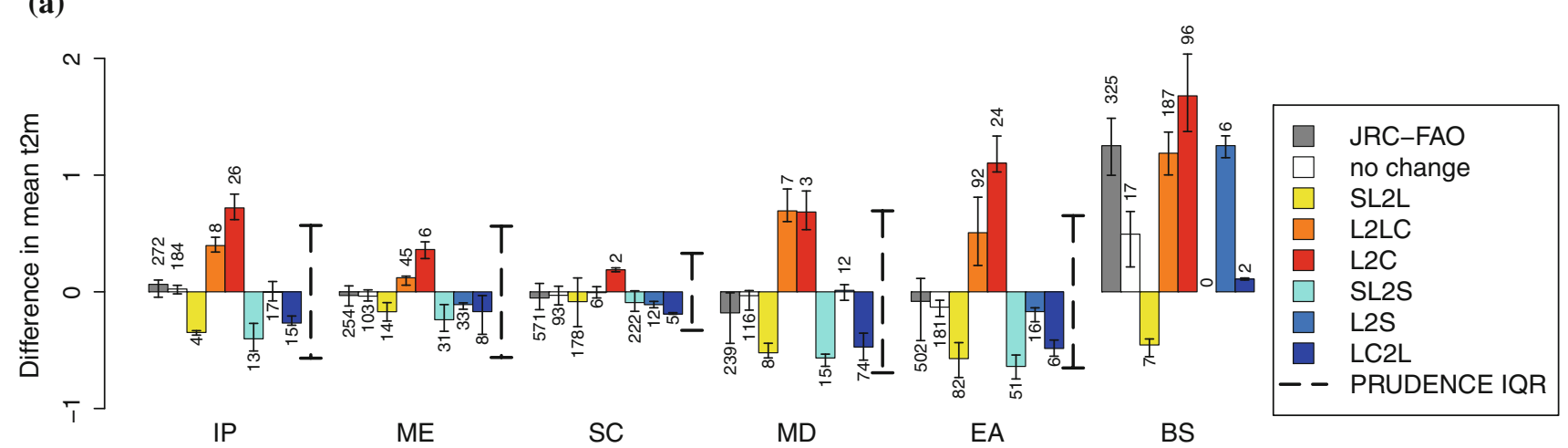

(b)

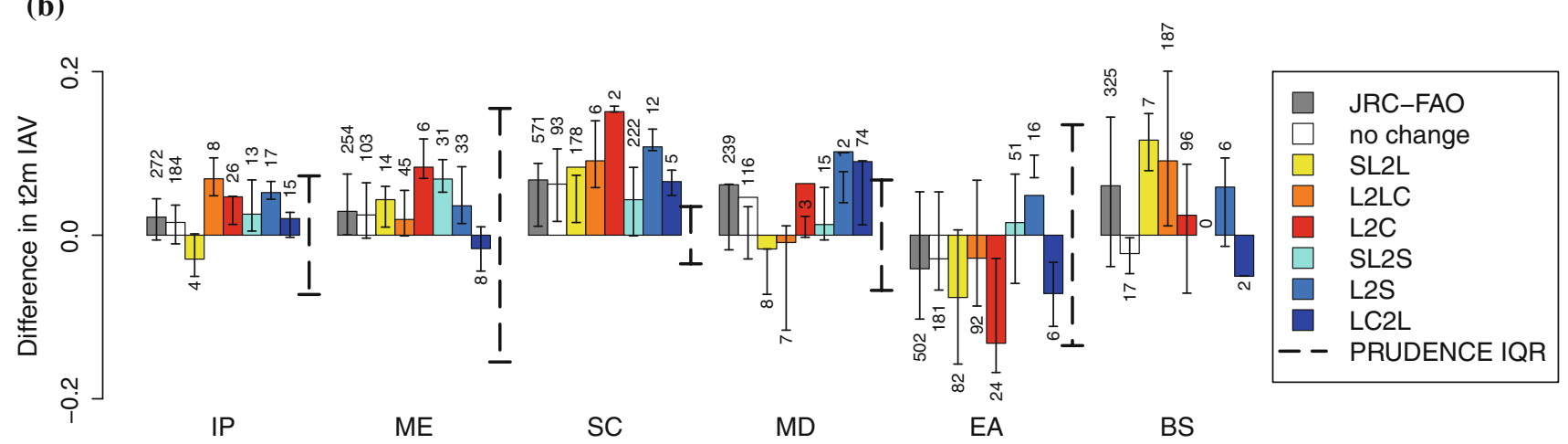

Fig. 5 Changes in summer 2-m temperature a mean and $\mathbf{b}$ interannual variability (standard deviation of JJA means) for selected regions. "JRC-FAO" refers to all land cells within the region, while "no change" refers to grid cells with the same soil type in the two simulations. Colored bars refer to grid points corresponding to soil type conversions. Error bars show the upper and lower quartiles of changes at individual grid cells and numbers indicate the number of grid cells available for each bars. "PRUDENCE IQR" refers to the interquartile range of models means from the PRUDENCE model

Figure 7c summarizes these findings; it displays the changes in EF with latitude for the main soil class conversions. There is indeed a tendency toward smaller changes in EF at high latitudes to some extent, although only two soil class conversions are present at these latitudes (SL2S and SL2L, in black and red, respectively) and thus it is difficult to generalize this statement. We note that these two soil class conversions are also those that show the largest spread in Fig. 7b, thus providing further support for our interpretation that the level of agreement between changes in EF and in SMI is affected by latitude. At latitudes lower than about 55 to $60 \mathrm{~N}$, no clear gradient can be identified.

Overall, changes towards a finer soil texture tend to lead to lower SMI, which in turn induces lower EF and thus leads to a warmer, mostly drier climate. The impact on temperature appears clearly, while the impact on precipitation remains more patchy. intercomparison experiment over the corresponding region, computed with the mean value of each model and plotted from $-\mathrm{IQR} / 2$ to $+\mathrm{IQR} / 2$. Values for PRUDENCE IQR are derived from Table 3 in Jacob et al. (2007). Iberian Peninsula (IP), Mid-Europe (ME), Scandinavia (SC), Mediterranaen (MD) and Eastern Europe (EA) are the largest regions as defined by Christensen and Christensen (2007) and an additional region North of the Black Sea (BS) is defined as 30 to $45^{\circ} \mathrm{E}, 45$ to $52^{\circ} \mathrm{N}$. Note that for the additional region $\mathrm{BS}$, data from PRUDENCE is not available

\subsubsection{Soil moisture-precipitation feedback}

Patterns of changes in precipitation are not as well related to soil class conversion patterns as patterns of changes in temperature. In most cases, regions of increased EF correspond to regions of increased precipitation, but there are exceptions. Although this behaviour is rather indicative of a positive soil moisture-precipitation coupling, there are also a few regions with an indication of negative soil moisture-precipitation coupling and/or of non-local effects. This confirms results from other studies, which have highlighted the possibility of both positive and negative coupling depending on the conditions and location (see e.g. Seneviratne et al. 2010, for a review). Nonetheless, it should be noted that the Tiedtke convection scheme used in this model version was found to mostly lead to positive soil moisture-precipitation feedback in a study for the alpine region (Hohenegger et al. 2009). As a final remark, one 
Fig. 6 Change in summer (JJA) soil moisture within the rootzone (JRC-FAO), expressed as two different measures: a Volumetric Water Content (VWC) (m); b Soil Moisture Index (SMI) (-). Note that a line smoothing has been applied for display purposes (a)

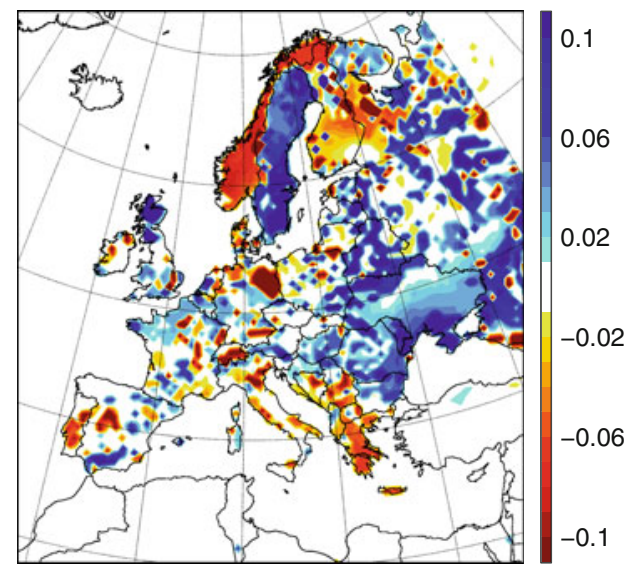

(a)

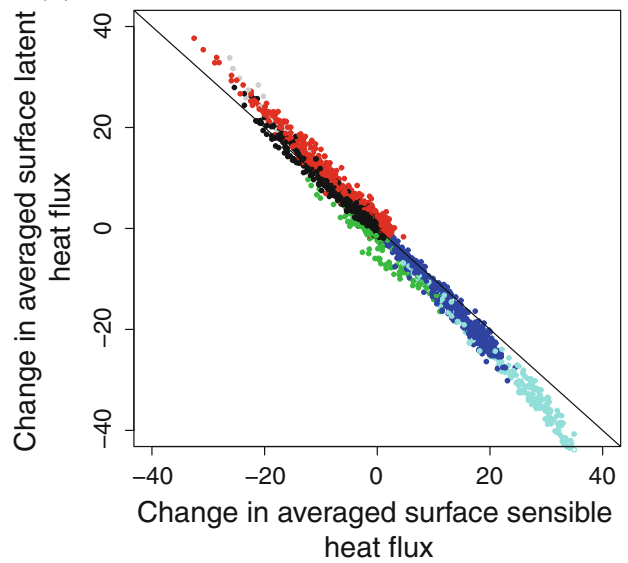

(c)

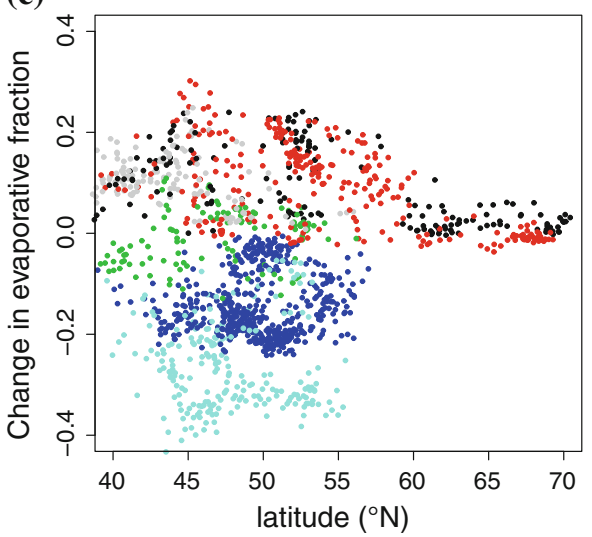

(b)

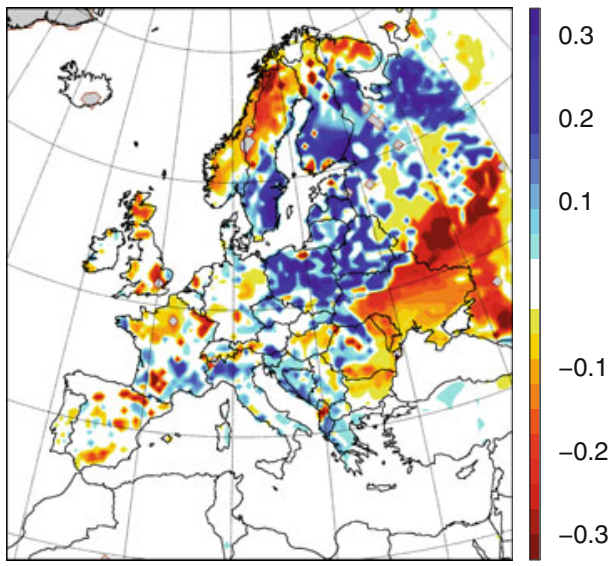

(b)

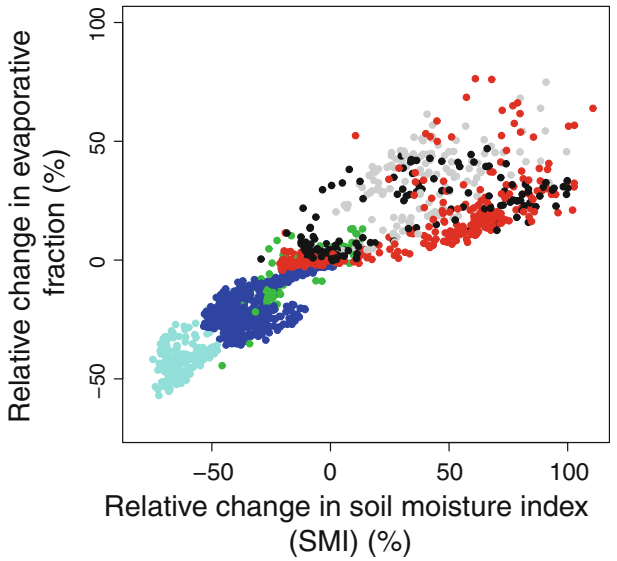

(d)

\begin{tabular}{|c|c|c|c|}
\hline \multicolumn{2}{|c|}{$\begin{array}{l}\text { soil type } \\
\text { conversion }\end{array}$} & $\begin{array}{c}\text { soil type } \\
\text { in FAO }\end{array}$ & $\begin{array}{r}\text { soil type } \\
\text { in JRC }\end{array}$ \\
\hline$\bullet$ & SL2S & sandy loam & sand \\
\hline$\bullet$ & SL2L & sandy loam & loam \\
\hline - & L2S & loam & sand \\
\hline - & L2LC & loam & loamy clay \\
\hline 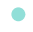 & L2C & loam & clay \\
\hline - & LC2L & loamy clay & loam \\
\hline
\end{tabular}

should consider that the final change in soil moisture level in the simulations results both from the change in soil class and from the modified precipitation.

\subsubsection{Interannual variability}

In addition to having an impact on the mean climate, the change in soil map also affects its interannual variability
(IAV). Figure $5 \mathrm{~b}$ shows changes in interannual variability for 2-m temperature, expressed as the standard deviation of summer means and compares it to inter-model interquartile range from the PRUDENCE experiment, in the same way as Fig. 5a shows it for the mean. Like for the mean, the total changes over each region (JRC-FAO) is generally smaller than the PRUDENCE IQR, although local effects can be large over some soil type conversions. Note that, for 
a given soil type conversion, IAV can increase or decrease depending on the region, while the sign of the effect on the mean is consistent throughout regions.

The largest effect on IAV occurs over Scandinavia, where the mean is only marginally affected. This results from the increase occuring for all soil type conversions in this region. Conversely, the effect over BS is small, unlike for the mean; In particular, the impact of the soil type conversion L2C is spread around 0.

Overall, changes in soil types affect interannual climate variability, but the underlying causes and the processes involved do not seem to be directly related to specific soil type conversions. A given soil type conversion can lead to both an increase or a decrease in IAV depending on the region, and the behaviour is therefore difficult to predict.

\subsection{Role of the individual soil parameters}

Among the six soil class conversions applied to the largest number of grid points (i.e. those displayed in Table 3), we consider three conversions in Sect. 3.2 (SL2L, L2LC, L2C). To some extent, $\mathrm{LC} 2 \mathrm{~L}$ is also covered since it is the opposite of L2LC, although we cannot exclude hysteresis effects. The two remaining conversions are not selected for further investigations: L2S exhibits very small changes in climate, while SL2S mainly concerns grid points far north of the continent (over e.g. Finland and Norway).

Changes in VWC, SMI and EF for each experiment in reference to FAO are shown in Fig. 8 as a function of latitude and are contrasted for the three soil class conversions. The impact of the individual parameter sets (DIFF, WHC, COND) is compared to the overall impact of the soil class conversion (JRC versus FAO).

For the three soil class conversions, changes in VWC mostly depend on $\theta_{\mathrm{FC}}$ and $\theta_{\mathrm{PWP}}$, as expected since these parameters modify the amount of water that can be stored in the soil. However, as highlighted in Sect. 3.1, VWC is not a good indicator of the impact on climate; therefore, SMI is also displayed in Fig. 8b, e, h. Changes in SMI are due to changes in two sets of parameters: $\theta_{\mathrm{FC}}$ and $\theta_{\mathrm{PWP}}$, on the one hand, and hydraulic diffusivity parameters $\left(D_{0}\right.$ and $D_{1}$ ) on the other hand, while hydraulic conductivity parameters $\left(K_{0}\right.$ and $\left.K_{1}\right)$ are not found to play a substantial role. Finally, changes in EF (Fig.8c, f, i) confirm this result: modifying hydraulic conductivity parameters alone does not substantially impact EF, implying a minor role of these parameters in our simulations; by contrast, both other sets of parameters (hydraulic diffusivity parameters; field capacity and plant wilting point) have a strong impact on EF. More specifically, for two soil class conversions (SL2L and L2C) field capacity $\theta_{\mathrm{FC}}$ and plant wilting point $\theta_{\mathrm{PWP}}$ explain most of the total changes in $\mathrm{EF}$ while hydraulic diffusivity parameters $\left(D_{0}\right.$ and $\left.D_{1}\right)$ also appears to contribute substantially to this change. The remaining soil class conversion (L2LC) shows the opposite behavior, with $\theta_{\mathrm{FC}}$ and $\theta_{\mathrm{PWP}}$ explaining a minor part of EF changes and $D_{0}$ and $D_{1}$ contributing to it more strongly.

Thus, these two sets of parameters impact the amount of moisture available for evapotranspiration and, thereby, EF. Interestingly, changes in EF are not always very well related to changes in SMI, despite our findings from Fig. 7. For instance, for the soil class conversion L2LC, changes in SMI at low latitudes are about the same for WHC-L2LC and DIFF-L2LC, while changes in EF differ substantially. This hints at other controls on EF than only water availability; for instance, the vertical transport of water within the soil may have been affected in a different way for these two simulations, which might in turn have affected the distribution of water within the soil layer and therefore EF in some situations, ultimately.

In all three cases, a joint increase in field capacity and plant wilting point $\left(\theta_{\mathrm{FC}}\right.$ and $\left.\theta_{\mathrm{PWP}}\right)$ leads to higher VWC, as expected since more water can be stored into the soil. Higher water available capacity $\theta_{A}$ leads to higher SMI and $\mathrm{EF}$, but a closer comparison of the soil class conversions $i$ ) L2C and ii) L2LC shows that this might be linked to other variables. First of all, and as indicated in Fig. 3, the change in $\theta_{A}$ is largest in L2C, although the values of $\theta_{\mathrm{FC}}$ and $\theta_{\mathrm{PWP}}$ change less than in L2LC. By contrast, the corresponding changes in EF (and SMI) are much larger in L2LC, which suggest that $\theta_{A}$ is not necessarily representative of changes in $\theta_{\mathrm{FC}}$ and $\theta_{\mathrm{PWP}}$. Changes in both field capacity $\theta_{\mathrm{FC}}$ and plant wilting point $\theta_{\mathrm{PWP}}$ are larger in L2LC and could explain this behaviour; however, indirect effects do probably play an important role as well. In particular, we note that larger changes in VWC in L2LC strongly impact hydraulic diffusivity $\left(D_{w}\right.$, see Eq. 18) which then further impacts SMI and its relationship to EF. Therefore, we conclude that both the available water capacity $\theta_{A}$ and the absolute values of $\theta_{\mathrm{FC}}$ and $\theta_{\mathrm{PWP}}$ play a substantial role.

Increasing hydraulic diffusivity $D_{w}$ leads to an increase in VWC. First, Eq. 18 shows that $D_{w}$ increases with increasing $D_{0}, D_{1}$ and VWC $(\theta)$, and that there is a feedback between VWC and $D_{w}$ since they influence each other. In the conversion SL2L, both $D_{0}$ and $D_{1}$ increase, leading to an enhanced hydraulic diffusivity. This increased diffusivity further enhances the VWC and forms a positive feedback loop. Similarly, in the conversion L2LC, a the decrease in both $D_{0}$ and $D_{1}$ is correlated with a decrease in VWC. For the last conversion (L2C), results are more difficult to interpret given that changes in $D_{0}$ and $D_{1}$ are of opposite sign and their relative importance can hardly be assessed due to the highly non-linear relationship between these two variables.

Interestingly, the vertical transport of water within the soil due to capillary forces appears to be a driving factor in 
(a)

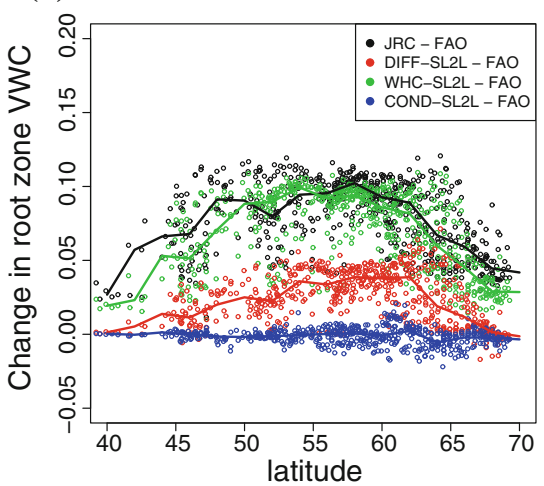

(d)

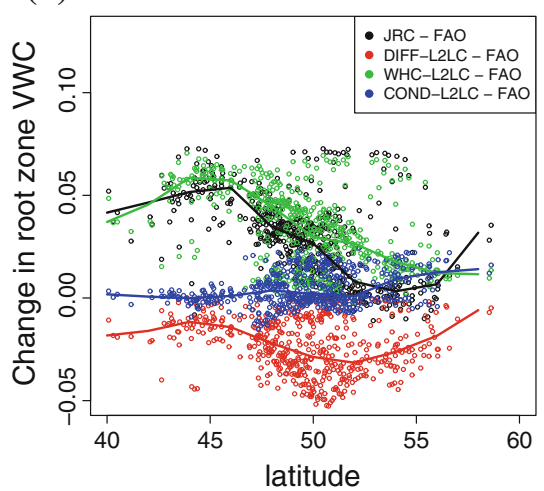

(g)

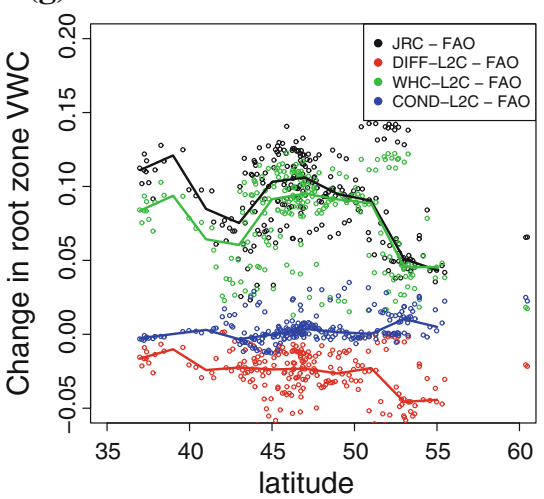

(b)

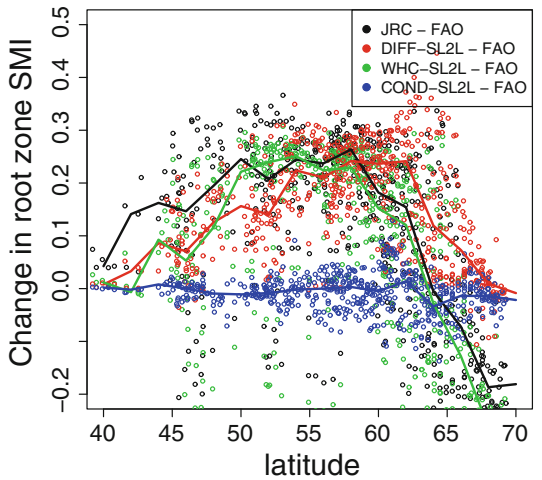

(e)

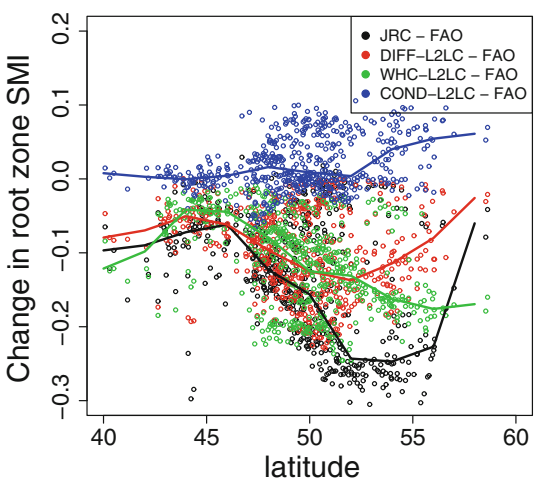

(h)

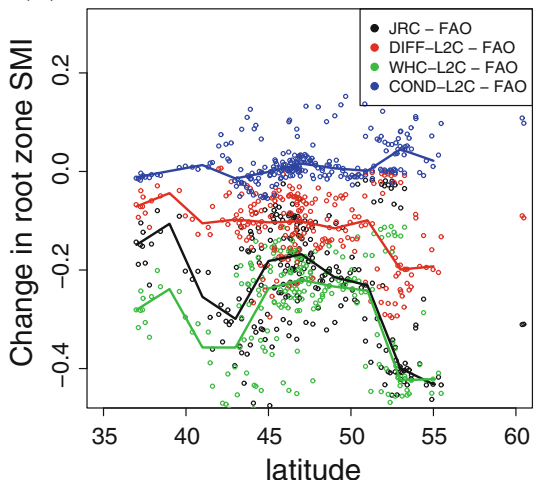

(c)

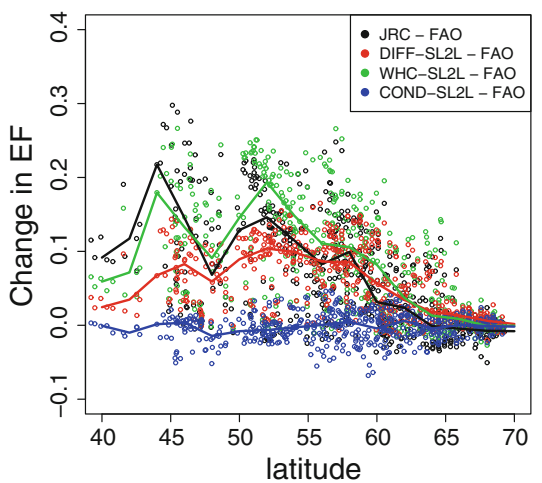

(f)

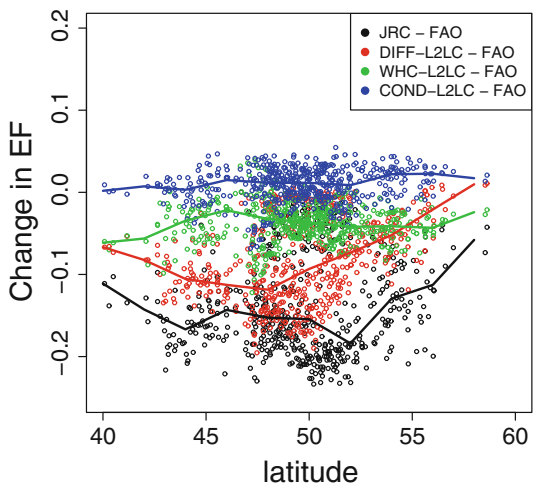

(i)

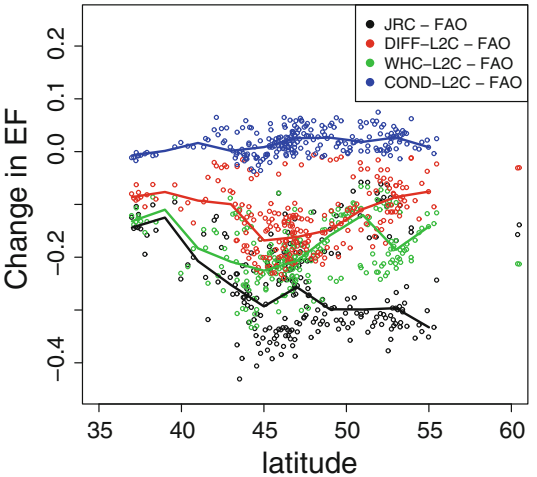

Fig. 8 Changes in VWC (left), SMI (center) and EF (right), with respect to FAO, versus latitude for JRC and the simulations with individual sets of parameters modified, for the three selected soil class conversion: sandy loam to loam (SL2L, top), loam to loamy clay (L2LC, middle), and loam to clay (L2C, bottom). VWC and SMI are computed over the root zone. Only the points for which JRC has the

our experiments. Indeed, the transport of water between the soil layers, which is expressed by Eq. 16, has two components. First gravitational drainage, expressed by $K_{w}$, is not critical in our simulations, since we find very little sensitivity of soil moisture and EF to $K_{0}$ and $K_{1}$. Second, capillary forces, represented by $D_{w}$ and the vertical gradient of water within the soil, play an important role as corresponding soil class conversion are shown. Lines show a running mean for bins of $2^{\circ}$ in latitude. a Change in VWC, SL2L, b Change in SMI, SL2L, c EF versus latitude, SL2L, d Change in VWC, L2LC, e Change in SMI, L2LC, f EF versus latitude, L2LC, g Change in VWC, L2C, h Change in SMI, L2C, i EF versus latitude, L2C

shown in simulations where $D_{0}$ and $D_{1}$ are modified. In addition to this direct effect, changes in $D_{w}$ through changes in VWC (Eq. 18) lead to a similar but indirect effect. Although it is difficult to disentangle this indirect effect from other possible effects due to changes in VWC, vertical profiles of soil moisture (Fig. 9) support this hypothesis: The experiments DIFF exhibit the vertical 
(a)

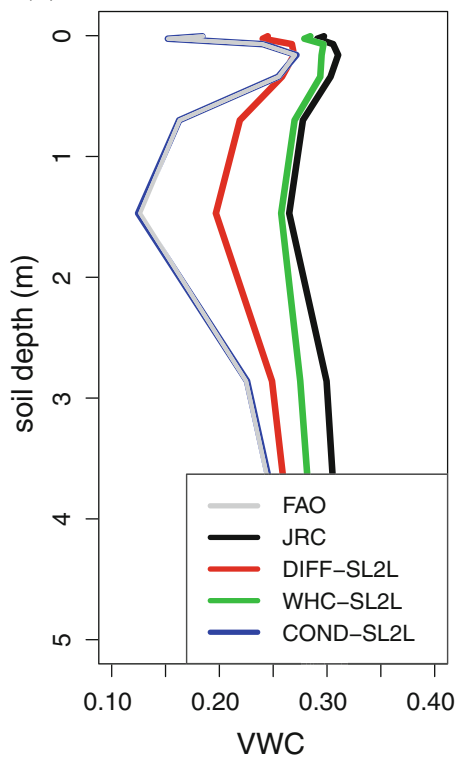

(d)

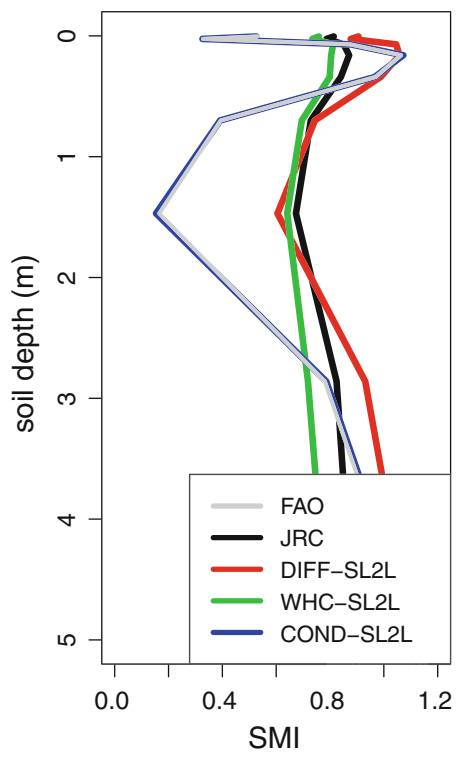

(b)

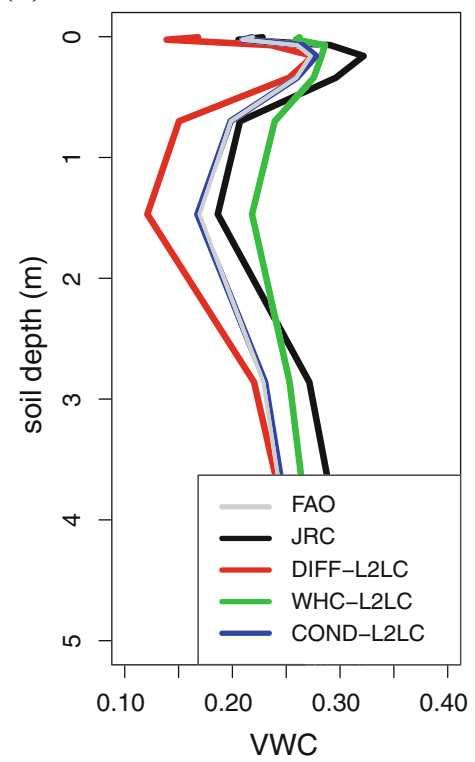

(e)

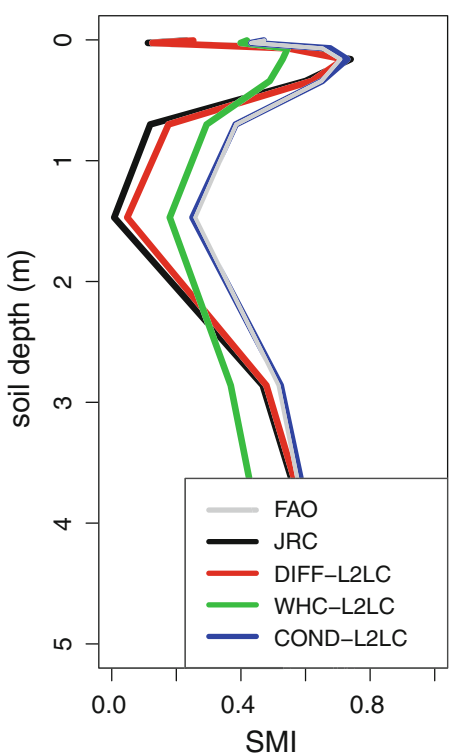

(c)

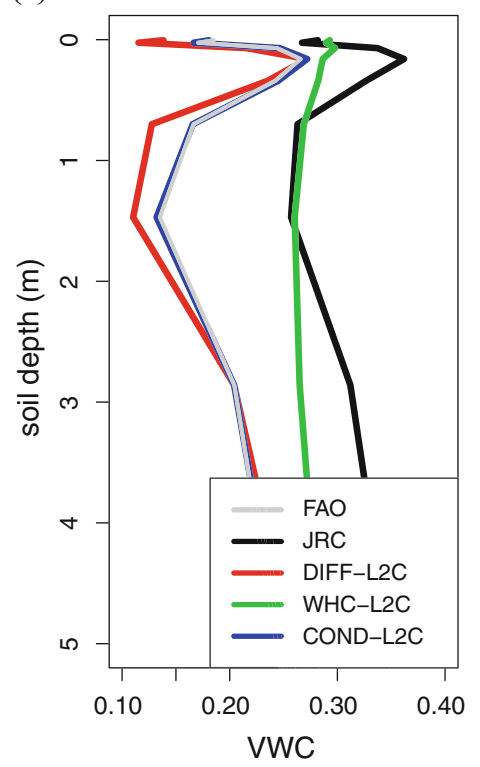

(f)

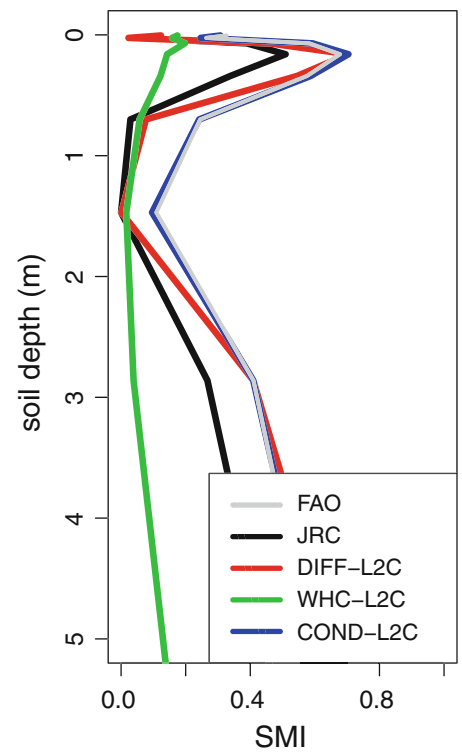

Fig. 9 Mean vertical profiles of volumetric water content (VWC) and soil moisture index (SMI) in summer for the three selected soil class conversions: sandy loam to loam (SL2L, left), loam to loamy clay (L2LC, middle), and loam to clay (L2C, right). Anaylses are done

profile of SMI closest to JRC, except for the soil class conversion SL2L where changes in hydraulic diffusivity parameters (in particular $D_{0}$ ) were small and other parameters dominate the observed effects. Vertical profiles of VWC show that, while experiments with modified WHC are closest to JRC in terms of mean and absolute value, the DIFF experiments exhibit the correct profile shape. In all cases, the COND experiments correspond exactly to the original FAO simulation, emphasizing the negligible role of hydraulic conductivity. This analysis highlights the fact only for the points for which JRC has the corresponding soil class conversion compared to FAO. All simulations are displayed for each conversion. a VWC, SL2L, b VWC, L2LC, c VWC, L2C, d SMI, SL2L, e SMI, L2LC, f SMI, L2C

that, in addition to SMI, the vertical redistribution of water within soil layers strongly impacts EF and the climate. In our experiments, the critical variable for this vertical distribution is hydraulic diffusivity.

The focus of this study is on the overall effect on the total evapotranspiration. Since transpiration is the main component of evapotranspiration in our simulations, it dominates our results. Changes in bare soil evaporation (not shown) were substantially different in all cases and they can help understand the underlying mechanisms. 
For instance, while in JRC this component was not much different from its value in FAO, in WHC-SL2L it differed substantially from FAO. In WHC-L2LC, bare soil evaporation even increased while it decreased in JRC. Both hydraulic conductivity and hydraulic diffusivity parameters did not play any substantial role for bare soil evaporation, and these results suggest that the parameters that control this component of $\mathrm{E}$ are quite different from those controlling transpiration.

Among the investigated parameters, the hydraulic diffusivity parameters $\left(D_{0}\right.$ and $\left.D_{1}\right)$ and field capacity $\theta_{\mathrm{FC}}$ and plant wilting point $\theta_{\mathrm{PWP}}$ explained most of the EF response in our soil class experiments. Our choice of parameters looks quite reasonable, since we reproduce this response to a large extent.

\section{Discussion and conclusions}

We performed and analyzed RCM simulations with different soil maps and soil parameters over Europe for the period 1980-2005. These experiments highlight the important role of soil parameters for summer climate, for the most part via their impact on EF, especially in regions where soil moisture is a limiting factor for evapotranspiration. This impacts the mean summer climate by up to about $2{ }^{\circ} \mathrm{C}$ for temperature and $20 \%$ for precipitation over regions with large differences between soil texture datasets, while the impact on interannual climate variability, which is found to be more difficult to relate to changes in soil texture, appears to be smaller, except for the increase over Scandinavia. Comparison with the multi-model analysis from PRUDENCE (Jacob et al. 2007) reveals that, over most regions, changes in mean summer 2-m temperature are small compared to inter-model interquartile range due to compensating changes within regions. However, over some regions such as North of the Black Sea, changes are as large as the PRUDENCE inter-model interquartile ranges of other regions (a direct comparison is not possible because PRUDENCE regions do not include this region). This shows that the choice of a soil dataset can potentially have an impact on the mean summer climate in some regions that is as large as the choice of the RCM itself.

More specifically, in simulations where individual parameters were modified, we identify the important role of parameters affecting the available water capacity (field capacity $\theta_{\mathrm{FC}}$ and permanent wilting point $\theta_{\mathrm{PWP}}$ ) as well as hydraulic diffusivity (parameters $D_{0}$ and $D_{1}$ ). In particular, the impact of $\theta_{\mathrm{FC}}$ and $\theta_{\mathrm{PWP}}$ on values of VWC and, therefore, on hydraulic diffusivity highlight the fact that, although a model-specific range of VWC might not be problematic for the parameterization of $\mathrm{E}$ if SMI is represented appropriately, the dynamic of soil moisture and its vertical profile is influenced by hydraulic diffusivity and, therefore, by absolute values. In other words, a model formulated in a similar was as in COSMO-CLM, i.e. with E parameterized mainly as a function of SMI and with hydraulic diffusivity/conductivity expressed as a function of VWC, needs correct values for both these soil moisture variables in order to model the processes in a correct way over time. Distinguishing strictly between the effect of field capacity and plant wilting point versus hydraulic diffusivity parameters, and their interactions, would have been interesting but is difficult, precisely because they are intimately related to one another. This could be done using methods of factor separation as described by e.g. Stein and Alpert (1993), but additional simulations would be required. Although we could not clearly distinguish between the effect of these two sets of parameters for these reasons, our results indicate an especially important role of $D_{w}$.

The results show a negligible sensitivity of soil moisture dynamics and profile to hydraulic conductivity, in contrast to the strong sensitivity to hydraulic diffusivity. Here, we recall that these two variables describe a single property of the soil, namely the ability of water to flow within it, but they express this property in different units (see "Vertical soil water transport" in Appendix 1). In the current formulation of the land-surface scheme TERRA_ML, $K_{w}$ represents the gravity term while $D_{w}$ represents capillary forces. Physically, these two parameters are intimately linked; therefore, modifying them independently is not fully realistic, but allows us to distinguish between the effect of gravitational drainage (through $K_{w}$ ) and capillary movement (through $D_{w}$ ). As expected, gravity only plays a marginal role in summer since the water content is almost always kept below field capacity. By contrast, capillary forces play an important role for the vertical motion of water within the soil. Note that, in some land-surface models (e.g. Community Land Model, see Lawrence et al. 2011), hydraulic conductivity accounts for the effects of both gravity and capillary forces. In these models, hydraulic conductivity is likely to play a key role, in a similar way as parameters controlling hydraulic diffusivity in TERRA_ML do.

The amplitude of the differences in mean summer climate for different soil classes (up to about $2{ }^{\circ} \mathrm{C}$ in $2-\mathrm{m}$ temperature and $20 \%$ in precipitation) provides evidence that the soil class plays an important role for the local climate in summer. Since the JRC soil map is assumed to be more accurate and up-to-date, one might expect improvements in the simulated climate with this new soil map, even at a coarse resolution. However, we note that COSMO-CLM does not perform better with the new JRC soil map. For instance, spatial root mean square error for summer mean 2-m temperature is larger in the region North 
of the black sea or over Poland (not shown). Several reasons may have contributed to this result. First of all, physical improvements in models do not necessarily lead to a reduction of bias, given the necessary preexisting model tuning. This is particularly true given the structure of the model and its heritage from BATS, which implies that retuning would probably be necessary. Second, the conversion of the original soil database from the JRC into TERRA_ML classes and the desired spatial resolution is subject to uncertainties, and the method used differs from the one used for the FAO soil map, due to different soil categories in the two original datasets (see Appendix 2). Finally, the values of the different soil parameters are critical, and these are subject to uncertainties as well. That said, this study focuses on the physical processes that lead to the simulated differences and not on improving model performance.

The region investigated in our study covers the European domain. We note that, in other regions, the processes involved might be different. In particular, other types of soils such as organic soils might play an important role, as shown by e.g. Lawrence and Slater (2008), who identified that the effect of soil carbon content on thermal and hydrological soil properties can lead to changes of about $2.5^{\circ} \mathrm{C}$ in mean summer $2-\mathrm{m}$ temperature.

In this study, we only investigate the effect on the mean climate and its interannual variability. However, since soil moisture is crucial for extremes events such as heat waves and droughts (e.g. Seneviratne et al. 2006a; e.g. Lorenz et al. 2010 e.g. Hirschi et al. 2011), soil parameters are expected to strongly impact these events. The representation of these effects would benefit from improved soil databases as well, which is crucial given their relevance for society. In addition, given the impact of soil properties on soil moisture dynamics and therefore on its memory and its impact on climate, not only climate simulations but also weather and seasonal forecasts would benefit from consistent databases of soil properties. Major issues include the discrepancy between models in the range and effect of parameters, the heterogeneity of soil parameters values in space and the variability of these parameters within a given soil class, which often exceeds their variability between classes.

Although much research has focused on the impact of land-use changes and related vegetation properties and their interactions with climate, which can even be investigated in details by LSMs that include dynamic vegetation, nothing comparable has been undertaken for soils. Given the large impact of soil specification on climate, soil classes could also be developed and included in a more dynamic way, at least for long-term climate simulations. Indeed, some soil physical properties can change depending on e.g. crops, crop management, land clearing and land use (Uhland 1950; Ghuman et al. 1991; Alegre and Cassel 1996; Zimmermann et al. 2006). In addition, interactions between soil and vegetation may play a role as well, as suggested by Osborne et al. (2004). For instance, the organic content of the soil can change relatively quickly after deforestation. Conversely, soil properties may subsequently impact vegetation and its development by providing conditions that favour certain species.

Finally, soil parameters being highly relevant in transitional regions between dry and wet climate given their relation to soil moisture dynamics and surface fluxes, disagreements between models with respect to land-climate interactions might be in part linked to these soil parameters as well (for instance land-atmosphere coupling, see Koster et al. 2004). Hence our results highlight the need to characterize soil class parameters in better detail in land surface and climate models.

Acknowledgments We thank Alessandro Dosio (JRC) for information about the European Soil Database. The European Soil Database (ESDB) has been developed by the Land Management \& Natural Hazards Unit of the European Commission Joint Research Centre, in the context of the development of European Environmental Data Centres by the European Commission and the European Environment Agency. We acknowledge partial funding from the CCES Maiolica project and the EU-FP7 EMBRACE project.

\section{Appendix 1: Parameterization of ET and vertical water transport in TERRA_ML}

This section described some selected aspects of TERRA_ML which are of particular relevance for our study. A more exhaustive documentation can be found at http:// www.cosmo-model.org/content/model/documentation/core/ default.htm.

\section{Evapotranspiration}

The parameterization of E is similar to that of the BATS model (Dickinson 1984). Evapotranspiration includes the following components in TERRA_ML:

- Bare soil evaporation $E_{b}$

- Plant transpiration $E_{p}$

- Evaporation from interception and the snow reservoir

Interception evaporation is negligible, as well as evaporation from snow reservoir since we concentrate on summer in the analysis. We thus focus here on $E_{b}$ and $E_{p}$.

Bare soil evaporation $E_{b}$ is parameterized as

$$
\begin{aligned}
E_{b}= & \left(1-f_{i}\right) \cdot\left(1-f_{\text {snow }}\right) \cdot\left(1-f_{\text {plant }}\right) \\
& \cdot \operatorname{Min}\left[-E_{\mathrm{pot}}\left(T_{\mathrm{sfc}}\right) ; F_{m}\right]
\end{aligned}
$$

where $F_{m}$ is the maximum moisture flux that the soil can sustain and $f_{\text {plant }}$ is the fractional vegetation area and 
is given as an external parameter field. $F_{m}$ is parameterized as

$F_{m}=\rho_{w} C_{k} D \frac{s_{t}}{\left(z_{u} z_{t}\right)^{1 / 2}}$

where $C_{k}$ is computed as

$C_{k}=1+1550 \frac{D_{\min }}{D_{\max }} \cdot \frac{B-3.7+5 / B}{B+5}$

with $B$ as defined for each soil class in Table 1 and

$D_{\text {min }}=2.5 \cdot 10^{-10} \mathrm{~m} / \mathrm{s}^{2}$

$D_{\max }=B \Phi_{0} K_{0} / \rho_{w m}$.

Here $\Phi_{0}=0.2 m$ is the soil water suction at saturation and $\rho_{w m}=0.8$ is the fraction of saturated soil filled by water, while $B$ and $K_{0}$ depend on the soil class (see Table 1). D is expressed as

$D=1.02 D_{\max } s_{u}^{B+2}\left(s_{t} / s_{u}\right)^{B_{f}}$

with $B_{f}$ given by

$B_{f}=5.5-0.8 B\left[1+0.1(B-4) \log _{10} \frac{K_{0}}{K_{R}}\right]$

with $K_{R}=10^{-5} \mathrm{~m} / \mathrm{s}$.

In Eqs. 2, 6, $s_{u}$ and $s_{t}$ are average values of soil water content normalized by the volume of void $\left(\theta_{\mathrm{PV}}\right)$ for two layers. These layers approximate Dickinson's layers $(0-0.1 \mathrm{~m}$ and $0-1 \mathrm{~m})$ by setting the lower boundary $\left(n_{u}\right.$ and $\left.n_{t}\right)$ as the lowest layer for which the lower boundary does not exceed $0.1 \mathrm{~m}$ and $1 \mathrm{~m}$, respectively.

$s_{u, t}=\frac{\sum_{k=1}^{n_{u}, t} W_{k}}{\theta_{\mathrm{PV}} \sum_{k=1}^{n_{u}, t} \Delta z_{k}}$

where $W_{k}$ is the water content of layer $k$ (in meters).

Plant transpiration $E_{p}$ is parameterized as

$E_{p}=f_{\text {plant }} \cdot\left(1-f_{i}\right) \cdot\left(1-f_{\text {snow }}\right) \cdot E_{\mathrm{pot}}\left(T_{\mathrm{sfc}}\right) r_{a}\left(r_{a}+r_{f}\right)^{-1}$

i.e. similarly to Dickinson (1984) but with additional assumptions (see online documentation for more details). Here, atmospheric resistance $r_{a}$ is given by $r_{a}^{-1}=C_{q}^{d}\left|v_{h}\right|=C_{A}$ and foliage resistance is given by $r_{f}^{-1}=r^{\prime} C_{F}=C_{V}$, with $C_{F}=f_{\mathrm{LAI}} r_{\mathrm{la}}^{-1}, r_{\mathrm{la}}^{-1}=C^{\prime} u_{\star}^{1 / 2}$ and $r^{\prime}=r_{\mathrm{la}}\left(r_{\mathrm{la}}+r_{s}\right)^{-1} \cdot f_{\mathrm{LAI}}$ is the leaf area index, given as an external parameter, and the stomatal resistance $r_{s}$ is defined by

$r_{s}^{-1}=r_{\text {max }}^{-1}+\left(r_{\text {min }}^{-1}-r_{\max }^{-1}\right)\left[F_{\text {rad }} F_{\text {wat }} F_{\text {tem }} F_{\text {hum }}\right]$

with $r_{\min }=150 \mathrm{~s} / \mathrm{m}$ and $r_{\min }=4,000 \mathrm{~s} / \mathrm{m}$. The functions $F$ describe the influence of the following conditions on the stomatal resistance: radiation $\left(F_{\text {rad }}\right)$, soil water content $\left(F_{\text {wat }}\right)$, ambient temperature $\left(F_{\text {tem }}\right)$ and ambient specific humidity ( $F_{\text {hum }}$ ), with $F=1$ for optimal conditions and $F=0$ for unfavorable conditions. In particular, we note the function describing the water limitation:

$F_{\text {wat }}=\operatorname{Max}\left[0 ; \operatorname{Min}\left(1 ; \frac{\theta_{\text {root }}-\theta_{\mathrm{PWP}}}{\theta_{\mathrm{TLP}}-\theta_{\mathrm{PWP}}}\right)\right]$

where $\theta_{\text {root }}$ is the liquid water content fraction of the soil averaged over the root depth, $\theta_{\mathrm{PWP}}$ is the permanent wilting point (see Table 1) and $\theta_{\text {TLP }}$ is the turgor loss point of plants, parameterized following Denmead and Shaw (1962) as

$\begin{aligned} \theta_{\mathrm{TLP}}= & \theta_{\mathrm{PWP}}+\left(\theta_{\mathrm{FC}}-\theta_{\mathrm{PWP}}\right) \cdot(0.81 \\ & \left.+0.121 \arctan \left(E_{\mathrm{pot}}\left(T_{\mathrm{sfc}}\right)-E_{\mathrm{pot}, \mathrm{norm}}\right)\right)\end{aligned}$

with $E_{\text {pot, norm }}=4.75 \mathrm{~mm} /$ day.

For these two components, potential evaporation $E_{\mathrm{pot}}$ is expressed as:

$E_{\mathrm{pot}}\left(T_{\mathrm{sfc}}\right)=\rho C_{q}^{d}\left|v_{h}\right|\left(q^{v}-Q^{v}\left(T_{\mathrm{sfc}}\right)\right)$

where $T_{\text {sfc }}$ is the temperation at the surface (uppermost soil layer for both $E_{b}$ and $E_{p}$ ), and $Q_{v}$ is the saturation specific humidity. $\left|v_{h}\right|$ is the absolute wind speed the the lowest grid level above the surface and $C_{q}^{d}$ is the bulk-aerodynamical coefficient for turbulent moisture transfert, calculated diagnostically.

\section{Vertical soil water transport}

The vertical water transport is based on Richards equation, which in the vertical direction is usually expressed as:

$\frac{\partial \theta}{\partial t}=\frac{\partial}{\partial z}\left[K_{w}\left(\frac{\partial \psi}{\partial z}+1\right)\right]$

where $\theta$ is the soil water content and $\psi$ is the water potential. On the right side of Eq. 14, $\frac{\partial \psi}{\partial z}$ refers to capillary forces, while 1 represents gravity. However, in TERRA_ML, this equation is expressed using only $\theta$ and not $\psi$. To do so, hydraulic diffusivity is introduced as $D_{w}=K_{w} \frac{\partial \psi}{\partial \theta}$ and thus

$K_{w} \frac{\partial \psi}{\partial z}=K_{w} \frac{\partial \psi}{\partial \theta} \frac{\partial \theta}{\partial z}=D_{w} \frac{\partial \theta}{\partial z}$

This leads to the equations used in TERRA_ML, where the soil water flux is expressed as

$F=-\rho_{w}\left[-D_{w} \frac{\partial \theta}{\partial z}+K_{w}\right]$

and the change over time in soil water content in each layer is defined as

$\frac{\partial \theta}{\partial t}=\frac{1}{\rho_{w}} \frac{\partial F}{\partial z}$.

Here, the vertical transport due to gravity and capillary forces is represented by $K_{w}$ and $D_{w}$, respectively. Note that 
hydraulic conductivity and hydraulic diffusivity represent the same physical characteristics of the soil, namely the ability of water to flow into it, but they express it in different units. The presence of both variables is specific to this modelling approach. In some other land-surface models (e.g. Community Land Model, see Lawrence et al. 2011), water potential is used and hydraulic diffusivity does not appear.

In addition, runoff is parameterized for any layer with $\theta>\theta_{\mathrm{FC}}$ and a negative divergence of the fluxes (16).

Hydraulic diffusivity $D_{w}$ and hydraulic conductivity $K_{w}$ depend on the water content $\theta$ as:

$D_{w}\left(\theta_{l}\right)=D_{0} \exp \left(D_{1} \frac{\left(\theta_{\mathrm{PV}}-\theta_{l}\right)}{\left(\theta_{\mathrm{PV}}-\theta_{\mathrm{ADP}}\right)}\right)$

$K_{w}\left(\theta_{l}\right)=K_{0} \exp \left(K_{1} \frac{\left(\theta_{\mathrm{PV}}-\theta_{l}\right)}{\left(\theta_{\mathrm{PV}}-\theta_{\mathrm{ADP}}\right)}\right)$.

$\theta$ is defined for each layer as $\theta_{l}=\frac{W_{l}}{\Delta z_{l}}$.

\section{Appendix 2: Conversion of the soil maps}

\section{FAO and JRC soil maps: raw data}

FAO The Soil map of the World released by the FAO is available at a resolution of 5 arc minutes and in geographical projection. The raw data used is taken from the Digital Soil Map of the World cd-rom (see http://www. fao.org/icatalog/search/dett.asp?aries_id=103540). The classification considers three classes reflecting soil texture: coarse, medium, and fine. For use in TERRA_ML, data from the top layer of the soil is considered.

JRC The Soil Geographical Database of Eurasia (SGDBE, see Lambert et al. 2002) at a scale of 1:1,000,000 is a digitized European map of the soil and related attributes. It is part of the European Soil Database, a product released in 2006 by the JRC (Morvan et al. 2008; Panagos et al. 2012) and available at http://eusoils.jrc.ec.europa.eu/ ESDB_Archive/ESDBv2/index.htm. It contains a large number of attributes, of which two are used in this study. These two attributes reflect the properties of the top layer of the soil, thus being consistent with the data used from the FAO soil map. The soil class is derived from the attribute "dominant surface textural class of the STU" ("TEXT_SRF_DOM"). This attribute contains the classes listed in Table 4. Non-soil classes are derived from the attribute "Soil major group code of the STU from the 1990 FAO-UNESCO Soil Legend" ("FAO90-LEV1"), which contains 28 soil categories and 6 non-soil categories. Nonsoil categories are listed in Table 5. More details about the attributes is given at http://eusoils.jrc.ec.europa.eu/ESDB_ Archive/ESDBv2/popup/sg_attr.htm.

\section{Conversion to TERRA_ML format: resolution and classes}

FAO The conversion of the raw data into TERRA_ML classes with the desired resolution is done using the PrEProcessor of time invariant parameters (PEP) of COSMOCLM (Smiatek et al. 2008). In this code, the number of points for each textural class (coarse, medium, fine) within a grid cell is determined and a weighted mean texture is computed. The assigned class in TERRA_ML is a function of this weighted mean. Ice, rock and peat are then added where the majority of points is belonging to one of these categories. The implementation in COSMO-CLM is also described by Doms et al. (2011).

JRC For input into COSMO-CLM, the JRC data was first resampled from its original $1 \mathrm{~km}$ resolution in Lamberts azimuthal projection to 1 arc second resolution in geographical projection by nearest neighbor interpolation. Classes were then converted to corresponding classes in TERRA_ML. For non-soil classes, the category "glacier" was converted to the class "ice" in TERRA_ML, while all other non-soil classes were converted to "rock", as shown in Table 5. However, non-soil classes were attributed only where there was no data available about the soil class in the attribute "TEXT_SRF_DOM" (i.e. where the value is 0). For soil classes, a conversion scheme was defined by refering to the look-up table described by Smiatek et al. (2008) and comparing it to the definition of the classes in Table 4 based on the proportion of clay, sand and silt. The resulting conversion scheme is shown in Table 6. Comparing the legend of the two classes in Table 6 gives us confidence in the chosen scheme. Note, however, that there is no ideal conversion scheme. For instance, here no class in the JRC data is converted to the TERRA_ML class "sandy loam" (coarse to medium). Conversely, the two classes "fine" and "very fine" in JRC are converted to the same class in TERRA_ML (clay, i.e. fine). These two cases illustrate the difficulty to translate a soil dataset with given soil categories into other categories, and, therefore, the associated uncertainties. Grid points where no information on both soil and non-soil categories was available (e.g. over North Africa) were filled using the original FAO soil map.

Finally, the aggregation at the model resolution $\left(0.44^{\circ}\right.$ in our case) is done using the COSMO-CLM PEP program as described by Smiatek et al. (2008). The method used in this program is the majority approach, i.e. the soil class with the 
Table 4 Categories of the attribute "TEXT_SRF_DOM" in the JRC soil map

\begin{tabular}{ll}
\hline $\begin{array}{l}\text { JRC soil class } \\
\text { (TEXT_SRF_DOM) }\end{array}$ & Definition \\
\hline No information & - \\
Coarse & $18 \%<$ clay and $>65 \%$ sand \\
Medium & $(18 \%<$ clay $<35 \%$ and $\geq 15 \%$ sand $)$ or \\
& $\quad(18 \%<$ clay and $15 \%<$ sand $<65 \%)$ \\
Medium fine & $<35 \%$ clay and $<15 \%$ sand \\
Fine & $35 \%<$ clay $<60 \%$ \\
Very fine & Clay $>60 \%$ \\
No mineral texture & Peat soils
\end{tabular}

Table 5 Non-soil categories of the attribute "FAO90-LEV1" in the JRC soil map and their conversion into TERRA_ML classes

\begin{tabular}{ll}
\hline $\begin{array}{l}\text { JRC non-soil class } \\
\text { (FAO90-LEV1) }\end{array}$ & TERRA_ML class \\
\hline Town & Rock \\
Soil disturbed by man & Rock \\
Water body & Rock \\
Marsh & Rock \\
Glacier & Ice \\
Rock outcrops & Rock
\end{tabular}

Note that this attribute contains 28 soil categories as well, such as Acrisol, Alisol, etc. These are not considered in the present study

Table 6 Conversion table of the soil classes from JRC (attribute "TEXT_SRF_DOM") to TERRA_ML

\begin{tabular}{lll}
\hline JRC soil class & TERRA_ML & \\
\cline { 3 - 3 } (TEXT_SRF_DOM) & Class & Short name (soil class) \\
\hline Coarse & Coarse & Sand \\
Medium & Medium & Loam \\
Medium fine & Medium to fine & Loamy clay \\
Fine & Fine & Clay \\
Very fine & Fine & Clay \\
No mineral texture & Histosols & Peat \\
\hline
\end{tabular}

Note that the scheme applied does not lead to any grid point with the soil class "sandy loam" in TERRA_ML. The columns for TERRA_ML follows Doms et al. (2011)

higher number of points within a grid cell is attributed to that grid cell.

\section{References}

Alegre JC, Cassel DK (1996) Dynamics of soil physical properties under alternative systems to slash-and-burn. Agric Ecosyst Environ 58:39-48
Anders I, Rockel B (2009) The influence of prescribed soil type distribution on the representation of present climate in a regional climate model. Clim Dyn 33:177-186

Betts AK (2004) Understanding hydrometeorology using global models. Bull Am Meteorol Soc 85:1673-1688

Bonan GB (2008) Forests and climate change: forcings, feedbacks, and the climate benefits of forests. Science 320:1444-1449

Christensen JH, Christensen OB (2007) A summary of the PRUDENCE model projections of changes in European climate by the end of this century. Clim Change 81:7-30

Davin EL, Seneviratne SI (2012) Role of land surface processes and diffuse/direct radiation partitioning in simulating the European climate. Biogeosci 9:1695-1707

Denmead O, Shaw R (1962) Availability of soil water to plants as aected by soil moisture content and meteorological conditions. Agron J 54:385-390

Dickinson RE (1984) Modelling evapotranspiration for three-dimensional global climate models. In: Hansen J, Takahashi T (eds) Geophysical monograph 29, Maurice Ewing vol 5, climate processes and climate sensitivity. American Geophysical Union, Washington, D.C, pp 58-72

Doms G, Foerstner J, Heise E, Herzog H-J, Mironov D, Raschendorfer M, Reinhardt T, Ritter B, Schrodin R, Schulz J-P, Vogel G (2011) A desciption of the nonhydrostatic regional model LM, Part II: physical parametrization. Technical Report DWD, 154 p

European Commission and the European Soil Bureau Network (2004) The European soil database distribution version 2.0. CD-ROM, EUR 19945

FAO (2003) Digital soil map of the world and derived properties. Rev. 1. (CD Rom). FAO Land and Water Digital Media Series CD-ROM

FAO/UNESCO (1974) Soil map of the World. UNESCO, Paris, France

Fischer EM, Seneviratne SI, Vidale PL, Luethi D, Schaer C (2007) Soil moisture-atmosphere interactions during the 2003 European summer heat wave. J Clim 20:5081-5099

Ghuman BS, Lal R, Shearer W (1991) Land clearing and use in the humid Nigerian tropics: 1. Soil physical-properties. Soil Sci Soc Am J 55:178-183

Grasselt R, Schuettemeyer D, Warrach-Sagi K, Ament F, Simmer C (2008) Validation of TERRA-ML with discharge measurements. Meteorol Z 17:763-773

Hirschi M, Seneviratne SI, Alexandrov V, Boberg F, Boroneant C, Christensen OB, Formayer H, Orlowsky B, Stepanek P (2011) Observational evidence for soil-moisture impact on hot extremes in southeastern Europe. Nat Geosci 4:17-21

Hohenegger C, Brockhaus P, Bretherton CS, Schaer C (2009) The soil moisture-precipitation feedback in simulations with explicit and parameterized convection. J Clim 22:5003-5020

Jacob D, Barring L, Christensen OB, Christensen JH, de Castro M, Deque M, Giorgi F, Hagemann S, Lenderink G, Rockel B, Sanchez E, Schar C, Seneviratne SI, Somot S, van Ulden A, van den Hurk B (2007) An inter-comparison of regional climate models for Europe: model performance in present-day climate. Clim Change 81:31-52

Kahan D, Xue Y, Allen S (2006) The impact of vegetation and soil parameters in simulations of surface energy and water balance in the semi-arid Sahel: a case study using SEBEX and HAPEXSahel data. J Hydrol 320:238-259. 3rd MOPEX workshop, Sapporo, JAPAN, JUL, 2003

GLACE Team: (2004) Regions of strong coupling between soil moisture and precipitation. Science 305:1138-1140

Lambert J, Daroussin J, Eimberck M, Le Bas C, Jamagne M, King D, Montanarella L, editors. (2002) The soil geographical database for Eurasia and the Mediterranean: instructions guide for elaboration at scale 1:1,000,000, Version 4.0. European Soil 
Bureau Research Report 8. Office for the Official Publications of the European Communities, Luxembourg

Lawrence D, Oleson K, Flanner M, Thorton P, Swenson S, Lawrence P, Zeng X, Yang Z-L, Levis S, Skaguchi K, Bonan G, Slater A (2011) Parameterization improvements and functional and structural advances in version 4 of the community land model. J Adv Model Earth Syst 3:1-27

Lawrence DM, Slater AG (2008) Incorporating organic soil into a global climate model. Clim Dyn 30:145-160

Lawrence PJ, Chase TN (2007) Representing a new MODIS consistent land surface in the community land model (CLM 3.0). J Geophys Res 112:G01023

Lorenz R, Jaeger EB, Seneviratne SI (2010) Persistence of heat waves and its link to soil moisture memory. Geophys Res Lett 37:L09703

Mölders N (2005) Plant- and soil-parameter-caused uncertainty of predicted surface fluxes. Mon Weather Rev 133:3498-3516. Workshop on short to medium-range numerical weather prediction in the Arctic and Antarctic, Fairbanks, AK, OCT, 2003

Morvan X, Saby NPa, Arrouays D, Le Bas C, Jones RJa, Verheijen FGa, Bellamy PH, Stephens M, Kibblewhite MG (2008) Soil monitoring in Europe: a review of existing systems and requirements for harmonisation. Sci Total Environ 391:1-12

Osborne T, Lawrence D, Slingo J, Challinor A, Wheeler T (2004) Influence of vegetation on the local climate and hydrology in the tropics: sensitivity to soil parameters. Clim Dyn 23:45-61

Panagos P, Van Liedekerke M, Jones A, Montanarella L (2012) European soil data centre: response to European policy support and public data requirements. Land Use Policy 29:329-338

Pitman AJ, de Noblet-Ducoudre N, Cruz FT, Davin EL, Bonan GB, Brovkin V, Claussen M, Delire C, Ganzeveld L, Gayler V, van den Hurk BJJM, Lawrence PJ, van der Molen MK, Mueller C, Reick CH, Seneviratne SI, Strengers BJ, Voldoire A (2009) Uncertainties in climate responses to past land cover change: first results from the LUCID intercomparison study. Geophys Res Lett 36:L14814

Richter H, Western A, Chiew F (2004) The effect of soil and vegetation parameters in the ECMWF land surface scheme. J Hydrometeorol 5:1131-1146

Rockel B, Will A, Hense A (2008) The regional climate model COSMO-CLM(CCLM). Meteorol Z 17:347-348

Schrodin R, Heise E (2001) The multi-layer version of the DWD soil model TERRA_LM. Technical report. Deutscher Wetterdienst

Seneviratne SI, Luethi D, Litschi M, Schaer C (2006) Land-atmosphere coupling and climate change in Europe. Nature 443:205-209

Seneviratne SI, Koster RD, Guo Z, Dirmeyer PA, Kowalczyk E, Lawrence D, Liu P, Lu C-H, Mocko D, Oleson KW, Verseghy D (2006) Soil moisture memory in AGCM simulations: analysis of global land-atmosphere coupling experiment (GLACE) data. J Hydrometeorol 7:1090-1112

Seneviratne SI, Corti T, Davin EL, Hirschi M, Jaeger EB, Lehner I, Orlowsky B, Teuling AJ (2010) Investigating soil moistureclimate interactions in a changing climate: a review. Earth Sci Rev 99:125-161

Smiatek G, Rockel B, Schaettler U (2008) Time invariant data preprocessor for the climate version of the COSMO model (COSMO-CLM). Meteorol Z 17:395-405

Stein U, Alpert P (1993) Factor separation in numerical simulations. J Atmos Sci 50:2107-2115

Teuling AJ, Uijlenhoet R, van den Hurk B, Seneviratne SI (2009) Parameter sensitivity in LSMs: an analysis using stochastic soil moisture models and ELDAS soil parameters. J Hydrometeorol 10:751-765

Uhland RE (1950) Physical properties of soils as modified by crops and management. Soil Sci Soc Am Proc 14:361-366

Zimmermann B, Elsenbeer H, De Moraes J (2006) The influence of land-use changes on soil hydraulic properties: implications for runoff generation. For Ecol Manag 222:29-38 